\title{
Cronología absoluta de los asentamientos tempranos del valle de Acarí
}

\section{Absolute chronology of the early settlements of the Acarí valley}

\author{
Lidio M. Valdez \\ https://orcid.org/oooo-0003-1931-2728 \\ University of Calgary, Canadá \\ lidiog@yahoo.es
}

\section{RESUMEN}

Las investigaciones arqueológicas realizadas en el valle de Acarí permiten discutir la dinámica de las antiguas ocupaciones humanas de este valle que es considerado como el límite sur de la región arqueológica-cultural conocida como la costa sur. Las raíces de la antigua ocupación humana de este valle están asociadas al sitio tipo de Hacha, perteneciente al Periodo Inicial. Las evidencias materiales, así como varios fechados absolutos, permiten asegurar que Hacha representa una larga y continua ocupación humana que se extendió entre los años 3398 a 2737 cal AP. Con posterioridad, nuevos asentamientos humanos parecen haber sido establecidos en las inmediaciones de Hacha, y con la cual este último fue abandonado. Paralelamente, otros asentamientos se habrían establecido en otros lugares del valle y sirvieron como base para las ocupaciones pertenecientes al Periodo Intermedio Temprano. Iniciando con Hacha, la alfarería desarrollada en este valle exhibe una continuidad, la misma que se extiende hasta mediados del Periodo Intermedio Temprano, periodo este cuando surgieron extensos asentamientos humanos distinguibles por la presencia de grandes fortificaciones.

En base a algunas evidencias, que aún no dejan de ser limitadas, se puede sostener que a finales del Horizonte Temprano las poblaciones de Acarí entraron en contac- 
to con las poblaciones ubicadas en los valles ubicados más al norte, como los de la cuenca del Río Grande e Ica. Dicha relación permitió la llegada de selectos artefactos norteños, siempre al contexto de una tradición local. Una ocupación propiamente Paracas, o Nasca, nunca parece haber ocurrido en Acarí. De este modo, el valle de Acarí empezó a mantener una relación continua con las diversas tradiciones culturales que se sucedieron en el tiempo y espacio en los valles arriba mencionados. Esta relación no sólo hizo de Acarí el último de la costa sur en mantener su orientación y asociación obviamente norteña, sino dicha orientación continuó por mucho tiempo, incluso hasta la ocupación Inka.

Palabras clave: Costa Sur; Periodo Inicial; Hacha; Periodo Intermedio Temprano; Acarí; tradiciones culturales.

\begin{abstract}
Archaeological research carried out in the Acarí Valley enables us discussing the dynamics of the early occupations in this valley regarded as the southern boundary of the archaeological-cultural region known as the Peruvian south coast. The foundation of the complex cultural development of Acarí can be found at the Hacha site that belongs to the Initial Period. Material evidence and several radiocarbon dates indicate that Hacha was occupied for a long time, from as early as 3398 to $2737 \mathrm{cal} \mathrm{BP}$. Subsequently, new human settlements seem to have been established in the vicinity of Hacha, following which the site was finally abandoned. At the same time, new settlements were established in other parts of the valley and became the foundation for a series of large settlements that flourished during the early phases of the Early Intermediate Period. Starting with Hacha, the pottery developed in this valley exhibits continuity, the same that extends until the middle of the Early Intermediate Period.
\end{abstract}

Sometime late during the Early Horizon, the inhabitants of Acarí were in contact with the peoples of the valleys found further to the north, which allowed the arrival of some northern artifacts. It appears that the Paracas or Nasca never established themselves in this valley. Thus, starting late during the Early Horizon, the peoples of Acarí maintained close and continuous relationship with the various cultural traditions that flourished in time and space in the valleys further to the north. This relationship not only made of Acarí the last valley of the south coast to maintain its northern orientation and association, but also this orientation continued for a long time, even until the Inka times.

Keywords: South Coast; Initial Period; Hacha; Early Intermediate Period; Acarí; cultural traditions.

Recibido: 10/01/2018 - AcePtado: 20/08/2020 - Publicado:25/06/2021 


\section{INTRODUCCIÓN}

Desde los tiempos de Bennett (1948), quien empezó a discutir los conceptos de áreas culturales, la costa sur del Perú es la región geográfica y cultural que abarca los diversos valles de la actual región de Ica. Dentro de este marco geográfico, el valle de Acarí (figura 01) es a menudo citado como el límite sureño de este espacio geográfico-cultural (Lanning, 1967, p. 32; Silverman, 1996, p. 96-97). Menzel (1959, p. 125) anotó, por un lado, la ausencia de una frontera geográfica o cultural precisa entre Chincha y los siguientes valles ubicados más al norte, como Cañete, y por el otro lado, la existencia de una marcada diferencia entre Yauca y los valles ubicados más al sur de Yauca. Dentro de este espacio geográfico que abarca desde Chincha hasta Acarí, en la opinión de Menzel, había una continuidad cultural que se inició durante el Horizonte Temprano y continuó hasta tiempos de la conquista Inka. Las observaciones de Menzel estaban basadas en el detallado estudio de la colección recuperada por Uhle del valle de Ica y depositada en Berkeley (Menzel, 1976, 1977), además de la posterior clasificación de la cerámica también proveniente de Ica hecha en cooperación con John Rowe y Lawrence Dawson (Menzel, Rowe \& Dawson, 1964) y el estudio de la cerámica recuperada durante los estudios efectuados en Tambo Viejo de Acarí en 1954.

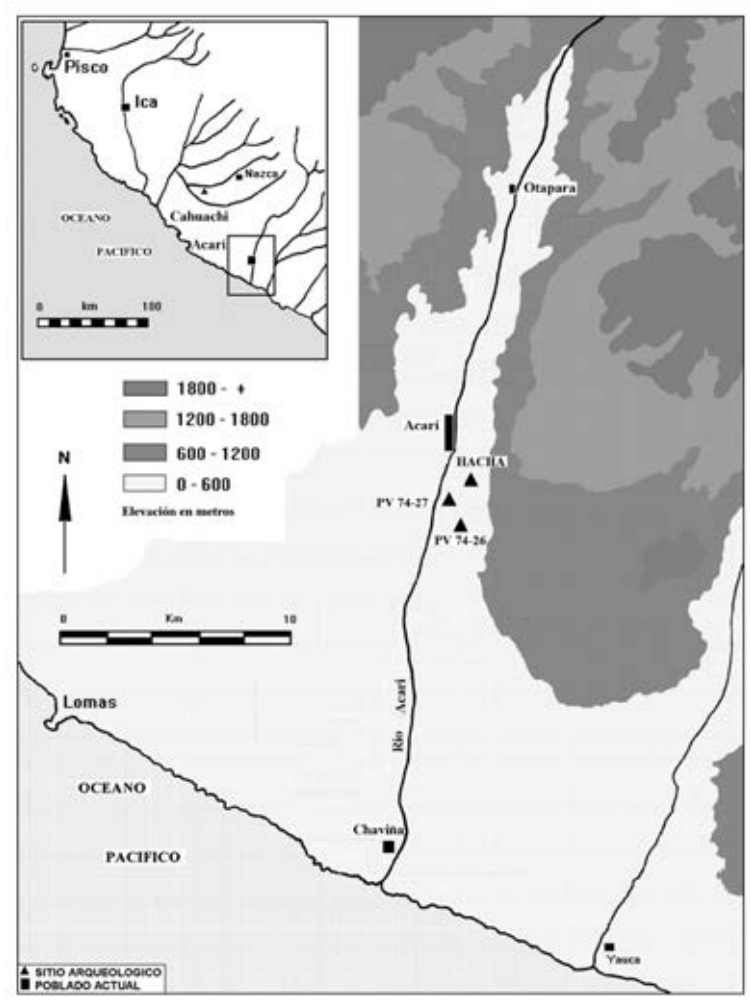

Figura 01. Ubicación de Hacha y otros asentamientos inmediatos ubicados en la sección media del valle de Acarí (L. M. Valdez) 
En este trabajo, es mi intención, primero, trazar los inicios de la investigación arqueológica en el valle de Acarí y, segundo, discutir la evidencia arqueológica relacionada a las ocupaciones más tempranas del valle. En particular, mi objetivo es discutir las ocupaciones tempranas de este valle a la luz de los fechados radiocarbónicos de los que se disponía a la fecha. Por algunas coincidencias, las investigaciones arqueológicas efectuadas en Acarí, no obstante ser limitadas, han prestado particular atención a las ocupaciones más antiguas. Dentro de este contexto, las investigaciones realizadas en Tambo Viejo relacionados con la ocupación Inka (Menzel, Riddell \& Valdez, 2012; Valdez, Menzel \& Riddell, 2014) son una excepción. Por lo tanto, en el resto de esta contribución se hace una evaluación de la evidencia hasta hoy conocida para el Periodo Inicial y para el Periodo Intermedio Temprano. Entre estos dos periodos de particular importancia en la antigua historia de Acarí aparece un periodo para el que se dispone de limitada información y como tal permanece poco conocido. En base a los datos limitados puestos a la luz durante los últimos tiempos, sin embargo, se adelantan algunas ideas que, tal vez, permitan enfocar nuestra atención a resolver interrogantes específicas y así esclarecer este periodo que en la actualidad aparece como un vacío dentro de una larga y compleja secuencia cultural.

\section{HISTORIA DE LA INVESTIGACIÓN ARQUEOLÓGICA EN ACARÍ}

Al igual que muchas otras regiones y valles de los Andes Centrales, el inicio de las investigaciones arqueológicas en el valle de Acarí está asociado a los primeros trabajos efectuados por Max Uhle, reconocido con acierto como 'padre de la arqueología peruana' (Rowe, 1954, p. 6-7). John H. Rowe sostiene que Uhle inició sus trabajos de investigación arqueológica en la costa sur durante el otoño peruano de 1900 y fue cuando llegó hasta Acarí (Carpio, 1942, p. 487; Rowe, 1954, p. 7; Lothrop \& Mahler, 1957, p. 3). Efectivamente, Lothrop y Mahler (1957, p. 3) citan una publicación de Uhle, donde este último anota, entre otros, que el cementerio de Chaviña, ubicado en las inmediaciones de la desembocadura del Río Acarí, forma parte de la región cuya exploración se acababa de iniciar. La inicial visita de Uhle al valle de Acarí parece haberse dado antes de su llegada a Ocucaje. Efectivamente, Rowe (1954) sostiene que Uhle habría llegado a Ocucaje recién en setiembre (primavera) de 1900. Rowe (1954, p. 11) también menciona otro recorrido de Uhle desde Acarí hasta Ica, durante el cual habría logrado recuperar una colección de cerámica Nasca temprano que posteriormente habría sido enviada a Berkeley. Desafortunadamente, Rowe no da mayores detalles con respecto a la exacta proveniencia de dicha colección de cerámica Nasca temprano.

Es de interés anotar que este fue el tiempo cuando Uhle había sido consultado por el gobierno peruano para establecer el Museo Nacional de Arqueología. Al respecto, Alfred L. Kroeber anota que la primera expedición efectuada por Uhle bajo la financiación del gobierno peruano parece haber sido al valle de Acarí (Kroeber, 1944, p. 23). Considerando que Uhle empezó a trabajar para el gobierno peruano en 
1905, la visita hacia Acarí debió haber ocurrido en dicho año. Otra fecha adicional proporcionada por Rowe (1954, p. 13) es el año 1909 cuando Uhle llegó a excavar en el cementerio de Chaviña. Posterior a la visita de Uhle, en 1913 Ales Hrdlička (1914) recorrió una buena sección del valle, llegando a inspeccionar varios sitios arqueológicos, entre estos a Chaviña, Tambo Viejo, y Huarato (Hrdlička, 1914, p. 29, 32.)

Queda incierto quien visitó la zona posterior a las varias expediciones efectuadas por Uhle, aunque existen algunas referencias (Carpio, 1942, p. 488; Lothrop \& Mahler, 1957, p. 3) que indican que Julio C. Tello condujo algunos trabajos en Acarí. En efecto, Lothrop y Mahler (1957, p. 3) citan una comunicación personal de Tello, quien se habría quejado del estado de destrucción de los sitios arqueológicos de Acarí como resultado de la huaquería. Donald Proulx todavía es más preciso y señala que Tello estuvo en Chaviña en 1915 (Proulx, 1989, p. 73). Es interesante anotar, además, que con ocasión del 25th Congreso Internacional de Americanistas efectuado en 1940 en Lima, Tello (1942, p. 694) anotó que la "cultura Nasca se extendió desde el valle de Pisco por el norte y el valle de Acarí por el sur." Esta observación debió haber estado basada en sus trabajos efectuados en Acarí. Con posterioridad, otra personalidad de prestigio internacional llegó hacia el valle de Acarí; él fue nada menos que Alfred L. Kroeber, quien entre 1925 y 1926 viajó desde Arequipa hacia Acarí (Kroeber, 1942, p. 5, 23), llegando a visitar al ya muy conocido sitio de Chaviña.

En los años cincuenta y continuando a los sesenta, se dieron los estudios de mayor significado tanto para la arqueología del valle de Acarí, como para la costa sur en general. Primero, entre 1952 y 1953 se llevó a efecto la Expedición Arqueológica de la Universidad de Columbia dirigida por William D. Strong, quien también llegó a visitar al sitio de Chaviña (Strong, 1957: Figure 1). Posteriormente, Víctor von Hagen dirigió la Expedición de los Caminos del Inca de la costa, prestando particular atención al sitio de Tambo Viejo del valle de Acarí (von Hagen, 1955). El siguiente año, John H. Rowe, en cooperación con el proyecto de von Hagen, dirigió la Cuarta Expedición Arqueológica de la Universidad de California al Perú (Rowe, 1956). Dorothy Menzel y Francis A. Riddell formaron parte de ambas expediciones (Valdez, 2009a), y en coordinación con von Hagen y Rowe llegaron a efectuar los primeros trabajos arqueológicos en Tambo Viejo en 1954 (Menzel \& Riddell, 1986; Menzel, Riddell \& Valdez, 2012; Bettcher \& Valdez, 2018; Valdez, 2018).

La primera experiencia de campo de Menzel está ligada al valle de Acarí (Valdez, 2011). Tal como se anotó líneas adelante, en 1954 Menzel y Riddell efectuaron los primeros trabajos de investigación arqueológica en Tambo Viejo, prestando particular atención al sector Inka. Menzel y Riddell también lograron recorrer una sección del valle y ubicaron varios sitios arqueológicos. Uno de los sitios ubicados por Menzel y Riddell fue Hacha perteneciente al Periodo Inicial (Rowe, 1963, 1967). Muestras de cerámica diagnóstica fueron recuperadas de la superficie de algunos 
de estos sitios. El análisis de dicha colección, más la familiaridad de Menzel con el material de Ica, permitió a estos investigadores concluir que "el valle de Acarí fue el último de la costa sur en tener una orientación y asociación predominantemente norteña" (Menzel \& Riddell, 1986, p. 105). Trabajos posteriores han confirmado que el material cultural del valle de Acarí guarda acercamientos de diverso orden con los materiales provenientes de los valles adyacentes ubicados al norte, en particular con Nazca e Ica (Menzel, Riddell \& Valdez, 2012; Menzel, Valdez \& Riddell, 2014).

La colección de cerámica recuperada de la superficie de los sitios ubicados por Menzel y Riddell fue posteriormente inspeccionada por Rowe. En base a dichas observaciones y posteriores visitas a los sitios inicialmente visitados por Menzel y Riddell, Rowe logró presentar la primera síntesis de la arqueología del valle de Acarí y la costa sur en general en su monumental artículo publicado en el número inaugural de la Revista Ñawpa Pacha (Rowe, 1963). De esta breve reseña, queda evidente que el valle de Acarí ha logrado atraer a nombres importantes dentro de la arqueología peruana, como son Uhle, Tello, Kroeber, Strong, Rowe y Menzel. Sin embargo, no todos los investigadores que lograron hacer sus investigaciones en este valle dejaron una documentación escrita, y si existen algunos, estos no dejan de ser breves referencias. En este sentido, John H. Rowe es una excepción. Rowe $(1956,1963)$ fue uno de los primeros en contextualizar la evidencia arqueológica de Acarí y quien dio a conocer a la comunidad científica de la existencia de importantes sitios arqueológicos en Acarí.

Por algunas coincidencias, los trabajos efectuados en Acarí han prestado - y siguen prestando - mayor atención a los sitios tempranos, como es el caso de Hacha (Rowe, 1967; Riddell \& Valdez, 1987; Robinson, 1994) y los sitios del Periodo Intermedio Temprano (Rowe, 1963; Valdez, 2006, 2009b, 2012a, 2013, 2014, 2017a, 2018). Por lo tanto, la suma de todos estos estudios, más los trabajos efectuados con posterioridad, permiten en la actualidad discutir temas que por mucho tiempo han permanecido al margen de toda discusión arqueológica. De todos los avances logrados hasta la actualidad, los fechados radiocarbónicos son de particular importancia, pues por primera vez permite acercarnos a determinar la duración de la ocupación de sitios específicos, como es el caso de Hacha. Lo aquí señalado, obviamente, no es la conclusión; más bien, este representa un primer avance y se espera que los esfuerzos continúen para así continuar aprendiendo más de las antiguas poblaciones que habitaron en este valle.

\section{HACHA Y EL PERIODO INICIAL}

Hacha representa no sólo el sitio arqueológico más temprano del valle de Acarí, sino también es el sitio más conocido de todo el valle de Acarí y la costa sur en general (Lanning, 1967, p. 81; Fung Pineda, 1988, p. 83; Willey, 1971, p. 111; Lumbreras, 1974, p. 52; Burger, 1995, p. 103). En el diario de campo de Francis A. Riddell de 1954 
(pp. 36-37), quedó registrado que Riddell y Menzel llegaron al sitio de Hacha el 21 de abril de 1954. Jorge Esparza, natural de Acarí y que venía trabajando con ellos en Tambo Viejo, fue quien informó a estos investigadores de un lugar donde abundaban puntas de obsidiana. Guiados por la curiosidad, Riddell y Menzel decidieron visitar el lugar en compañía de Esparza; al recorrer el sitio no encontraron las puntas de obsidiana, pero sí observaron la abundante presencia de instrumentos hechos en basalto que parecían ser hachas. La ocurrencia de dichos artefactos fue la razón por la cual Riddell y Menzel decidieron identificar el sitio con el nombre de Hacha. Riddell y Menzel también encontraron fragmentos de un tipo único de cerámica que hasta entonces era desconocido y que en la superficie aparecía asociado a los instrumentos de basalto.

Mientras Menzel y Riddell continuaban con sus estudios en Tambo Viejo, John H. Rowe visitó Acarí y fue informado por Menzel y Riddell de la existencia de muchos sitios, incluido el sitio de Hacha. En base a toda esa información, en su reporte de 1956, Rowe (1956) dio a conocer a la comunidad científica de la existencia del sitio de Hacha, resaltando a su vez su temprana ubicación cronológica (ver figura 01). En el diario de campo de Rowe de 1959 (cuya copia me envió gentilmente en 1999), él llegó al sitio por primera vez en 1959. En la página 127 del mencionado diario, Rowe incluye un croquis de acceso al sitio y dos páginas más adelante aparece otro croquis que detalla la ubicación de Hacha y de los otros sitios ubicados en las inmediaciones de Hacha. Desafortunadamente, el diario no provee una fecha exacta de cuándo Rowe llegó al sitio, excepto el año. En las siguientes páginas (pp. 133-145) del referido diario de campo, Rowe describe en detalle lo observado en la superficie del sitio, dando crédito a su vez a Riddell y Menzel como los primeros en ubicarlo y por identificarlo con el nombre de Hacha. Esta sección del referido diario de campo es de mucha importancia para el estudio de las ocupaciones tempranas de este valle en tanto que muchos de los sitios visitados y observados por Rowe (y originalmente por Menzel y Riddell) ya no existen en la actualidad.

En la página 129 del diario de campo, Rowe menciona que la cerámica presente en el sitio es "muy distintiva y antigua que cualquier otro conocido en Acarí." Rowe también da referencia a los varios cortes hechos en el sitio por Jorge Esparza, los mismos que habrían expuesto diversas estructuras que parecían haber sido construidas de tapia. Una de tales estructuras estaba en la parte norte del sitio y donde Rowe llevó adelante algunas excavaciones. En base al croquis elaborado por Rowe y que aparece en la página 130 de su diario de campo, dicha estructura es la misma identificada por Robinson (1994) como estructura 2. Entre otros, en algunas paredes de la mencionada estructura aparecen escenas pictográficas, identificadas como representaciones de camélidos (Riddell \& Valdez, 1987; Valdez, 1996) e indica que este fue una estructura especial. 
Rowe volvió al sitio de Hacha en agosto de 1962, esta vez en compañía de Thomas Patterson. En diciembre de 1997, Patrick Carmichael me hizo llegar una copia del diario de campo de Patterson, a quien de inmediato solicité su autorización para citar sus notas no publicadas. Patterson aceptó mi petición de manera muy gentil. En diario de campo de Patterson da crédito que Patterson y Rowe llegaron al sitio de Hacha el 19 de agosto de 1962 e hicieron una colección de cerámica de la superficie. Patterson, al igual que Rowe (ver arriba), da referencia a los cortes del tractor hechos por Esparza. Patterson anota, además, que tres muestras de carbón fueron recuperadas de la sección norte del sitio.

Las notas de Patterson son bien detalladas y mencionan, por ejemplo, la presencia en Hacha de varios tipos de restos, tanto animales como vegetales. Al referirse a los restos de plantas, Patterson fue hábil al constatar la ausencia del maíz. Además, Patterson es el primero - de lo que conozco- en referirse a la cerámica tipo Hacha. Finalmente, Patterson menciona el hallazgo de varias piezas de figurinas antropomorfas fragmentadas, hechas en arcilla no cocida, identificadas como las más antiguas para toda la región. Alexandra Morgan había recibido de J. H. Rowe fotografías de las mencionadas figurinas. Las imágenes que aparecen en la figura 02 son copias que A. Morgan compartió conmigo.

En base a estos trabajos iniciales, especialmente de Rowe, Hacha es generalmente citado como el sitio tipo con cerámica inicial para toda la costa sur del Perú. Sin embargo, la información proporcionada por Rowe $(1963,1967)$ es bastante limitada, y de los diarios de campo tanto de Rowe, como de Patterson, se puede sostener que la mayoría de los datos nunca fueron publicados. Por ejemplo, Patterson menciona que él y Rowe hicieron una colección de cerámica de la superficie de Hacha; a la fecha se desconoce en absoluto de dicha colección y ni una sola pieza ha sido publicada y menos ilustrada.

Entre 1984 y 1986 Roger Robinson llevó adelante trabajos de excavación arqueológica en el sitio de Hacha (Robinson, 1994). Los trabajos dirigidos por Robinson pusieron al descubierto nuevas evidencias que permitieron discutir aspectos relacionados a la tecnología lítica, formas arquitectónicas, subsistencia, formas de enterramiento y cerámica (Riddell \& Valdez, 1987, Valdez, 2000b). Las excavaciones conducidas por Robinson también permitieron determinar que las estructuras de Hacha fueron construidas en base a bloques de barro unidos con argamasa que posteriormente fueron enlucidos con barro, dando así la impresión de tapia. Los muros son bajos y no superan el metro de altura. De este modo, los muros sólo constituyeron la base de las estructuras. Efectivamente, en la parte superior de los muros aparecen una serie de hoyos pequeños y en algunos casos se hallaron restos de postes en los mismos hoyos. Estos hallazgos sugieren que los postes sirvieron para proyectar los muros. Por lo tanto, en su parte superior las estructuras de Hacha fueron de quincha. 


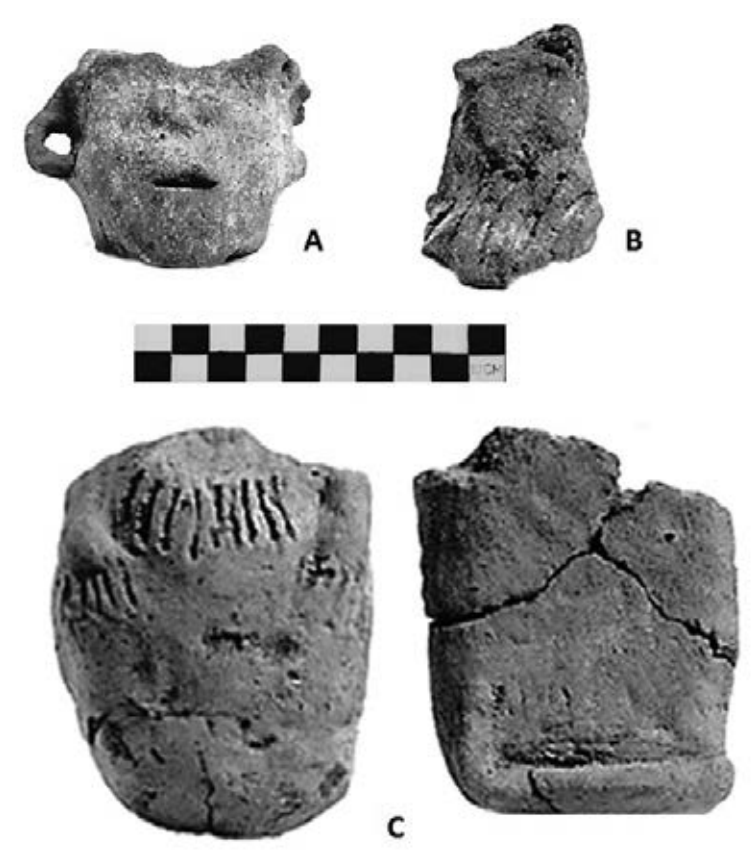

\section{Figura 02. Figurinas de arcilla no cocida provenientes de Hacha (cortesía de Alexandra Morgan; escala en centímetros)}

Las excavaciones efectuadas en Hacha permitieron recuperar e identificar una variedad significativa de plantas (Cuadro 1), las mismas que continuaron siendo cultivadas durante los periodos posteriores en Acarí y la costa sur en general (Beresford-Jones, 2011, p. 88-89; Piacenza, 2002; Valdez, 2010b, p. 80-82). Tal como Patterson observó inicialmente, el maíz es una excepción en tanto que recién aparece en sitios de ocupaciones posteriores. Al mismo tiempo, los trabajos dirigidos por Robinson permitieron identificar una variedad numerosa de recursos marinos, en particular los moluscos (Riddell \& Valdez, 1987). De esta evidencia queda evidente que los habitantes de Hacha explotaron recursos del valle, así como otros provenientes del mar, no obstante que el sitio está a más de $20 \mathrm{~km}$ del océano.

Con las excavaciones en Hacha se lograron recuperar varias muestras de carbón para los propósitos de obtener fechados absolutos (Riddell \& Valdez, 1987, p. 7; Robinson, 1994, p. 36). Sumados a los fechados (UCLA) obtenidos inicialmente por Rowe (1967), en total existen 10 fechados para Hacha (Cuadro 2). David Beresford-Jones tuvo la gentileza de efectuar la calibración de los fechados de Hacha, además del modelo bayesiano. Dicho análisis determinó que el sitio de Hacha fue inicialmente establecido alrededor del año 3398 y abandonado aproximadamente alrededor del año 2737 cal AP (antes del presente). Esto indica que Hacha fue habitado aproxima- 
Cuadro 1: Relación de plantas cultivadas identificadas en 4 sitios arqueológicos de Acarí

\begin{tabular}{|l|c|c|c|}
\hline Plantas & Hacha & Amato / Huarato & Gentilar \\
\hline Maní (Arachis hypogaea) & $\mathrm{X}$ & $\mathrm{X}$ & $\mathrm{X}$ \\
\hline Maíz (Zea mays) & & $\mathrm{X}$ & $\mathrm{X}$ \\
\hline Camote (Ipomoea batatas) & $\mathrm{X}$ & $\mathrm{X}$ & $\mathrm{X}$ \\
\hline Achira (Canna edulis) & $\mathrm{X}$ & $\mathrm{X}$ & $\mathrm{X}$ \\
\hline Yuca (Manihot esculenta) & & $\mathrm{X}$ & $\mathrm{X}$ \\
\hline Jicama (Pachyrrhizus tuberosus) & & $\mathrm{X}$ & $\mathrm{X}$ \\
\hline Ají (Capsicum sp.) & & $\mathrm{X}$ & \\
\hline Frijol (Phaseolus vulgaris) & $\mathrm{X}$ & $\mathrm{X}$ & $\mathrm{X}$ \\
\hline Pallar (Phaseolus lunatus) & & $\mathrm{X}$ & $\mathrm{X}$ \\
\hline Canavalia (Canavalia sp.) & $\mathrm{X}$ & $\mathrm{X}$ & \\
\hline Palillo (Campomanesia lineatifolia) & & $\mathrm{X}$ & \\
\hline Guayaba (Psidium guajava) & $\mathrm{X}$ & $\mathrm{X}$ & \\
\hline Pacae (Inga feuillei) & & $\mathrm{X}$ & $\mathrm{X}$ \\
\hline Lúcuma (Pouteria lúcuma) & & $\mathrm{X}$ & $\mathrm{X}$ \\
\hline Huarango (Prosopis sp.) & & $\mathrm{X}$ & $\mathrm{X}$ \\
\hline Calabaza (Cucurbita moschata) & & & \\
\hline Zapallo (Cucurbita máxima) & & $\mathrm{X}$ & \\
\hline
\end{tabular}

damente por 500 años. Durante su larga existencia, los pobladores de Hacha desarrollaron una subsistencia orientada hacia la explotación de los recursos del valle, especialmente al cultivo de una variedad de plantas. Esta fue complementada con el uso de los recursos renovables del mar y la caza de animales silvestres, al parecer de guanacos. La ocurrencia en la superficie de Hacha de las puntas de proyectil hechas de obsidiana sugiere que la caza fue de mucha importancia.

A partir de las excavaciones en Hacha, Robinson logró distinguir 2 tipos de cerámica. El primero está constituido por los fragmentos presentes en la superficie del sitio, pero que, en la opinión de Robinson, aún carecen no sólo de una ubicación estratigráfica, sino también de fechados absolutos. Esta es la típica cerámica Hacha (Riddell \& Valdez, 1987: figuras 03 \& 04), identificada por Robinson como Hacha 2. Esta es la cerámica que guarda acercamientos estilísticos, por ejemplo, con la cerámica Muyo Moqo de Waywaka, Andahuaylas (Grossman, 1972, 1985, p. 48, 57). Las muestras hasta hoy recuperadas constituyen ollas sin cuello de cuerpo globular - como las de Muyo Moqo- así como jarras, cuencos y platos, todas de paredes del- 
Cuadro 2. Fechados radiocarbónicos calibrados y modelados del sitio de Hacha.

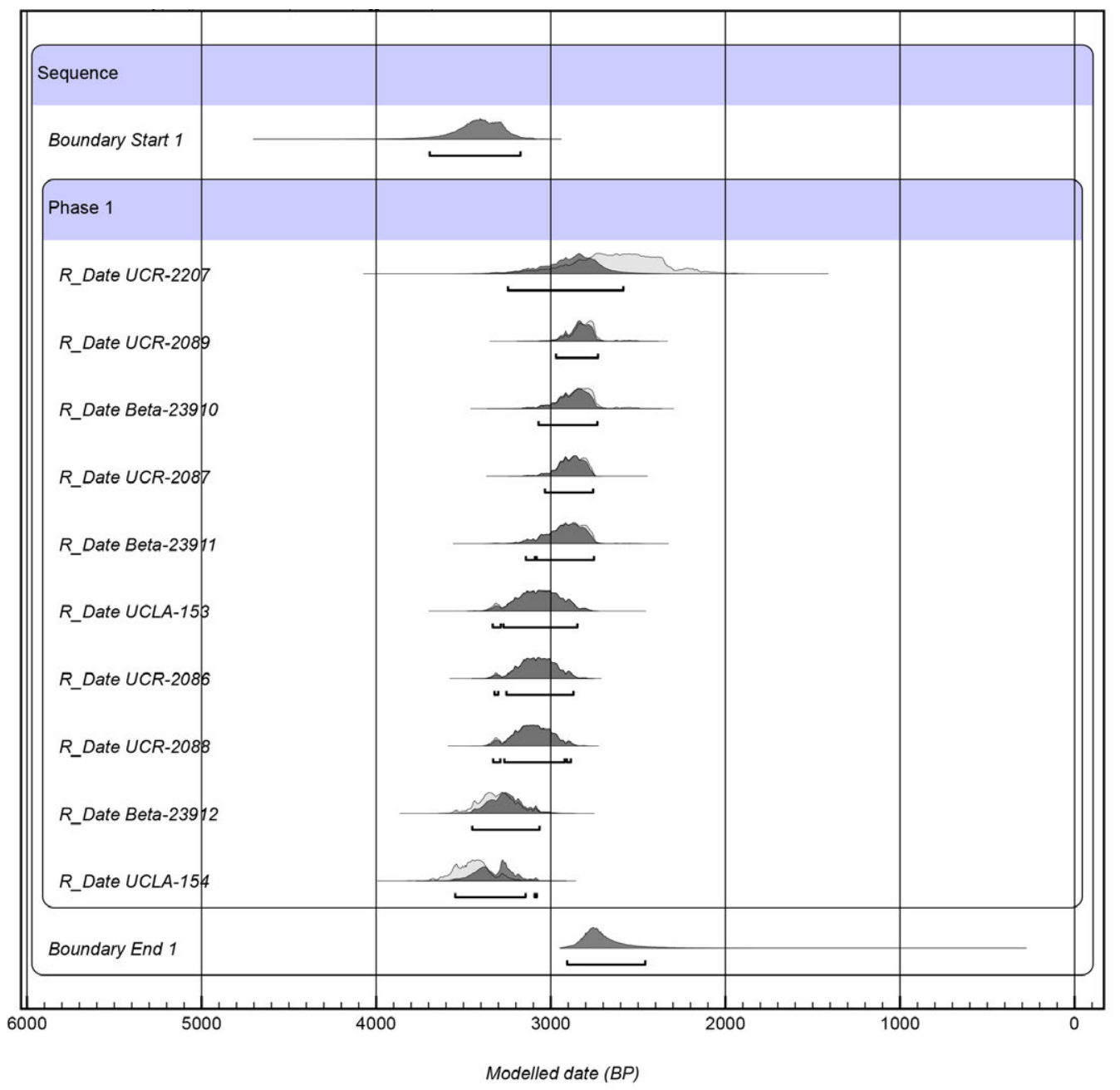

gadas. La pasta es de color gris oscuro y marrón rojizo, y está compuesta de arcilla con abundante presencia de arena no seleccionada, además de cuarzo, feldespato, y mica, añadidas como desgrasantes. Por último, la textura es bastante compacta y sugiere que la cocción se hizo a temperaturas bastante elevadas.

En la opinión de Robinson (1994, p. 12), la superficie de la cerámica Hacha 2 está fuertemente erosionada. Sin embargo, durante mi más reciente inspección superficial (agosto 2012), encontré ejemplares no erosionados. En dichas muestras fue posible determinar que tanto la superficie externa, como la interna, recibieron un tratamiento especial que incluye el alisado, estriado, pulido y presencia de engobe rojo natural. En su diario de campo, Patterson también hace referencia a un fragmento con "engobe rojo y decoración negativa, pintada horizontalmente en bandas 
y puntos." Sobre dicha superficie aparecen varias formas de decoración consistentes de sellos hundidos (utilizando algún material tubular) que ocurren en forma alineada, formando una línea o varias líneas, y generalmente cerca al borde de las vasijas. Además, aparecen puntos alineados y concéntricos elaborados sobre áreas con apliqué, colocadas también cerca a los bordes. Todas estas formas de decoración aparecen en la superficie externa. Sólo en un caso se observó la ocurrencia de incisiones formando líneas, las mismas que ocurren tanto en la superficie interna, como en la superficie externa. El tratamiento final de las vasijas fue mediante las técnicas del bruñido y ocasionalmente un ligero pulido. Como resultado, ambas superficies tienden a ser suaves. Esta variedad de cerámica, presente en la superficie del sitio, es identificada por Robinson (1994, p. 12-13) como 'Hacha 2' y, en su opinión, carece de un fechado absoluto y una asociación precisa.

A su vez, Robinson (1994, p. 14) distinguió una segunda variedad de cerámica identificada como 'Hacha 1'. En la opinión de Robinson, esta variedad nunca ha sido recuperada en la superficie del sitio y hasta la fecha se conoce sólo del hallazgo hecho en asociación a la estructura 4 de Hacha. No obstante que el número de ejemplares recuperados es pequeño, Robinson asegura que es notable la diferencia entre este (Hacha 1) y la cerámica presente en la superficie (Hacha 2). A diferencia de Hacha 2, Robinson sostiene que la pasta es bastante fina y con inclusiones (desgrasantes de arena) no sólo finas, sino también muy homogéneas. El color de la pasta es un rojo oscuro, y al fragmentarse estas piezas dejan una línea uniforme, al parecer también distinta del tipo anterior. Ambas superficies presentan un baño de engobe muy fino y de color gris y marrón oscuro que posteriormente fue pulido, dejando de este modo una superficie muy suave. Las formas consisten en cuencos y copas, una de las cuales es rectangular, una forma desconocida en el tipo anterior.

Con la excepción de los dos fechados obtenidos por Rowe (1967), al parecer de contextos asociados a la estructura 2 de Robinson (1994), el resto de los fechados existentes para el sitio están asociados con el tipo de cerámica Hacha 1. Estratigráficamente, Robinson sostiene que Hacha 1 está ausente en la superficie del sitio y su ocurrencia sólo se conoce de contextos provenientes de la subsuperficie.

Mi más reciente inspección del sitio demuestra que las "dos variaciones de cerámica de Hacha" sí ocurren en la superficie de Hacha. En particular, piezas identificables como 'Hacha 2' (figuras 03 \& 04) aparecen en la superficie, al lado de fragmentos cuyas superficies están erosionadas. Es más, existe una considerable variación de formas e incluye botellas, forma esta anteriormente no reportada para el sitio. Anteriormente, Menzel, Rowe y Dawson (1964, p. 258) ya habían hecho resaltar que las tempranas manifestaciones de botellas de doble pico con asa-puente estaban precisamente en Hacha. Esta breve información deja en claro que, no obstante que el sitio ha sido discutido por más de cinco décadas, queda mucho que aprender de Hacha. 
Del mismo modo, la propuesta hecha por Robinson (1994) necesita ser tomada con cautela hasta que nuevos estudios más detallados se efectúen en el sitio.

\section{EL HORIZONTE TEMPRANO EN ACARÍ}

En contraste con el Periodo Inicial, lo sucedido en Acarí después que el sitio de Hacha fue abandonado aún permanece incierto. Las prospecciones arqueológicas efectuadas a mediados de los años ochenta por los integrantes del California Institute for Peruvian Studies dirigido por Francis A. Riddell no llegaron a ubicar sitio alguno asignable al periodo Formativo. Una excepción vendría a ser el sitio de Paqla, ubicado en la parte alta del valle, donde se hallaron dos pequeños fragmentos de cerámica con incisiones, encontrados en las inmediaciones de estructuras mortuorias ya profanadas (Riddell \& Valdez, 1988, p. 83). Al interior de dichas estructuras de piedra se logró observar la presencia de varios esqueletos humanos y cráneos
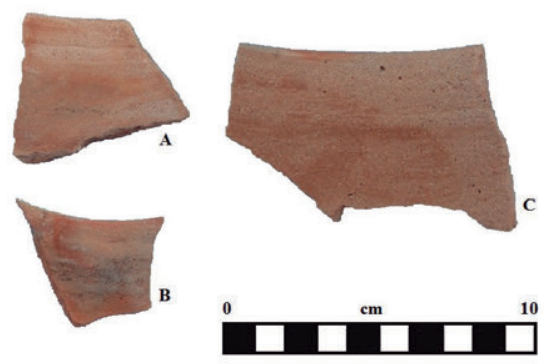

Figura 03. Cerámica del estilo Hacha (L. M. Valdez)

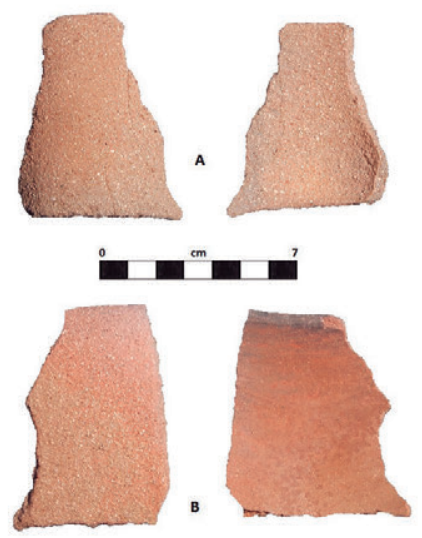

Figura 04. Cerámica del estilo $\mathrm{Ha}$ cha; observe el engobe en la superficie interna (lado derecho; L. M. Valdez)

con una deformación de tipo fronto-occipital. Sin embargo, es poco lo que se puede sostener en base a estos dos fragmentos hasta que estudios sistemáticos se efectúen en el sitio.

En 1959 Rowe ubicó un pequeño montículo inmediatamente al sur del sitio de Gentilar y al oeste de Hacha, sitio este que fue catalogado como PV 74-27 (ver figura 01). En la página 131 de su diario de campo, Rowe anota haber encontrado en la superficie del referido sitio fragmentos de cerámica que "podrían ser Paracas tardío (T4)." Durante mis varias visitas al sitio de Gentilar (Valdez, 1994), pasé en más de una ocasión por dicho lugar, donde también observé fragmentos de cerámica simi- 
lares a los presentes en los otros sitios considerados como pertenecientes a las fases tempranas del Periodo Intermedio Temprano. En la página 129 de su diario de campo, Rowe menciona otro sitio ubicado esta vez al sur de Hacha, denominado Elsar, y catalogado como PV 74-26. En dicho sitio Rowe señala haber encontrado cerámica Nasca 1 y "tal vez algunos ejemplares de T4." Helaine Silverman (1977) da referencia al sitio de Elsar e indica que este representa una ocupación Nasca 1. La observación de Silverman posiblemente está basada en el diario de campo de Rowe. Lamentablemente, Rowe nunca publicó algo en particular; por lo tanto, se desconoce el detalle del tipo de material que él haya encontrado en PV 74-26 y PV 74-27.

Recientemente, en un esfuerzo para verificar lo mencionado por Rowe y recuperar alguna muestra tangible, visité los sitios arriba mencionados, pero sin encontrar material alguno que pueda ser identificado con seguridad como Paracas Tardío o Nasca temprano. Para el caso de Elsar (PV 74-26) no fue posible ubicar una sola estructura y mucho menos cerámica de alguna utilidad para los propósitos de esta discusión. Los tiestos encontrados son definitivamente diferentes de los presentes en la superficie de Hacha, pero estilísticamente difíciles de determinar si pertenecen al Horizonte Temprano en tanto que las muestras no son diagnósticas. Por su parte, en la superficie de PV 74-27 existen algunos fragmentos de cerámica similares a los hallados en los sitios fortificados pertenecientes a las fases tempranas del Periodo Intermedio Temprano, mientras que un mayor número de fragmentos pertenecen a las fases finales del Periodo Intermedio Temprano. La ocurrencia de dicho material sugiere que PV 74-27 es parte del sitio de Gentilar que precisamente representa una ocupación de las fases finales del referido periodo.

Desafortunadamente, muchos de los sitios inicialmente visitados por Rowe han sido fuertemente modificados y en lo peor de los casos desaparecidos por completo. Como resultado, a la fecha, es difícil confirmar, o negar, las iniciales observaciones de Rowe con respecto a la posible presencia de material T4 en los sitios arriba mencionados. Sin embargo, y como se discute más adelante, la numerosa presencia de sitios pertenecientes a las fases tempranas del Periodo Intermedio Temprano deja abierta la posibilidad que las ocupaciones pertenecientes al Horizonte Temprano, tal vez, están aún por ser encontradas.

Durante un reconocimiento del sitio de Amato en 1987 se halló un fragmento de cerámica con incisiones lineales en la superficie externa. El fragmento pertenece a un cuenco de pared delgada y fina, de superficie pulida y de color gris oscuro. En base a este hallazgo, inicialmente sostuve que Amato tal vez fue originalmente establecido a finales del Horizonte Temprano (Valdez, 2000b, p. 21). Como se discute en la siguiente sección, los recientes fechados absolutos obtenidos para los contextos de Amato precisamente apuntan hacia un establecimiento bastante temprano del sitio. Además, y confirmando en parte lo sostenido con anterioridad, con las excavaciones 
efectuadas en Amato se hallaron algunos ejemplares de cerámica con decoración incisa. La primera, y la más llamativa, es una imagen de un ser antropomorfo de ojos redondos, dientes pronunciados y una cara redondeada (figura 05). La imagen fue pintada con un color blanco lechoso y un rojo ocre, y ambos colores son separados por líneas incisas. Por cuanto las pinturas fueron aplicadas después de la cocción, y considerando que "los cambios estilísticos que marcan el inicio de la fase Nasca 1 son el uso del engobe aplicado antes de la cocción, en lugar de la pintura de resina aplicada después de la cocción, como un medio de producir diseños policromos de cerámica fina" y que en "Nasca 1 los nuevos colores de engobe fueron generalmente separados por líneas incisas, en el mismo sentido como las pinturas de resina fueron utilizados con anterioridad" (Menzel, Rowe \& Dawson, 1964, p. 251), este fragmento antecede a Nasca 1 o es contemporáneo con Nasca 1.

Al mismo tiempo, un pequeño grupo de seis fragmentos similares al anterior fueron hallados también en Amato. Los fragmentos provienen del nivel más profundo de una unidad excavada al interior del céntrico recinto rectangular. En este caso, todos los fragmentos fueron pintados con rojo ocre y negro, mientras que las líneas que separan los colores son también incisiones. Sin embargo, y a diferencia del fragmento anterior, los colores fueron aplicados antes de la cocción. Como tales, estos fragmentos son identificables como, o contemporáneos con, Nasca 1. Merece anotar que todos estos fragmentos son de paredes delgadas, finas, y posiblemente pertenecen a vajillas, como copas y cuencos. Tecnológicamente estos fragmentos son diferentes de los fragmentos que abundan en el sitio, lo que sugiere que estas posiblemente corresponden a piezas manufacturadas en algún valle ubicado más al norte de Acarí y posteriormente introducidas hacia Acarí.

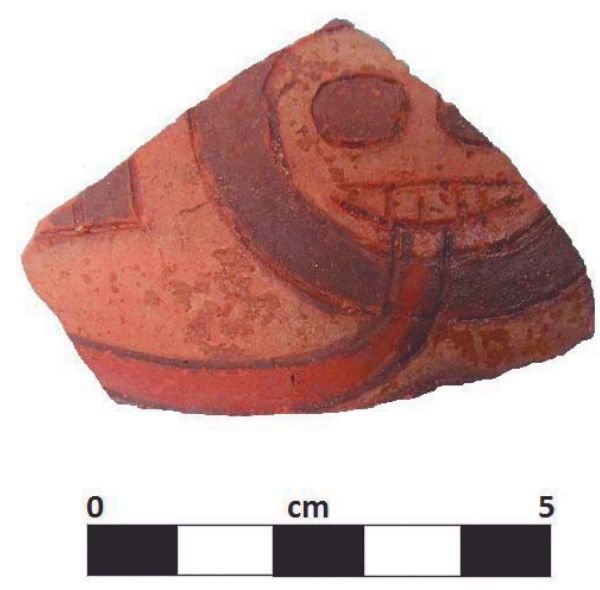

Figura 05. Cerámica con decoración incisa y pintura pre-cocción proveniente de Amato (L. M. Valdez) 
Finalmente, las excavaciones en Amato también permitieron exponer varios entierros (Valdez, 2006), de los cuales destaca uno en particular. Al lado exterior este del recinto rectangular se expusieron dos tumbas en urnas. Ambas urnas contenían los restos de infantes (Valdez et al., 2010, p. 44-47); pero, aquel del lado este (Tumba 1) se distingue del otro por la presencia de una pequeña banda bordada con representaciones de cabezas humanas (figura 06), la misma que había sido colocada alrededor de la cabeza del infante. Los motivos de representación también podrían ser figuras en miniatura de individuos con los cabellos largos y tal vez de sexo femenino. Considerando que representaciones similares son conocidas para contextos tanto Paracas tardío como Nasca temprano, la evidencia proveniente de Amato es otro indicador de que el sitio fue inicialmente establecido a finales del Horizonte Temprano y que continuó durante las primeras fases del Periodo Intermedio Temprano. Al mismo tiempo, el tejido en mención y sus representaciones en particular parecer ser una imitación a diseños probablemente Paracas o Nasca. De ser correcta esta observación, estaríamos frente a una situación donde los residentes del valle de Acarí no sólo mantuvieron algún tipo de contacto son los habitantes de los valles ubicados más al norte, sino también el interés de por lo menos algunos miembros de la población de Acarí en representar motivos foráneos.

Estos hallazgos son limitados y a la vez novedosos y dejan abierta la posibilidad de que en el curso de futuros trabajos en Amato, y los otros sitios del Periodo Intermedio Temprano de este valle, salgan nuevas luces. Eso ayudará considerablemente a explicar mejor lo que sucedió en Acarí entre el abandono de Hacha y el posterior

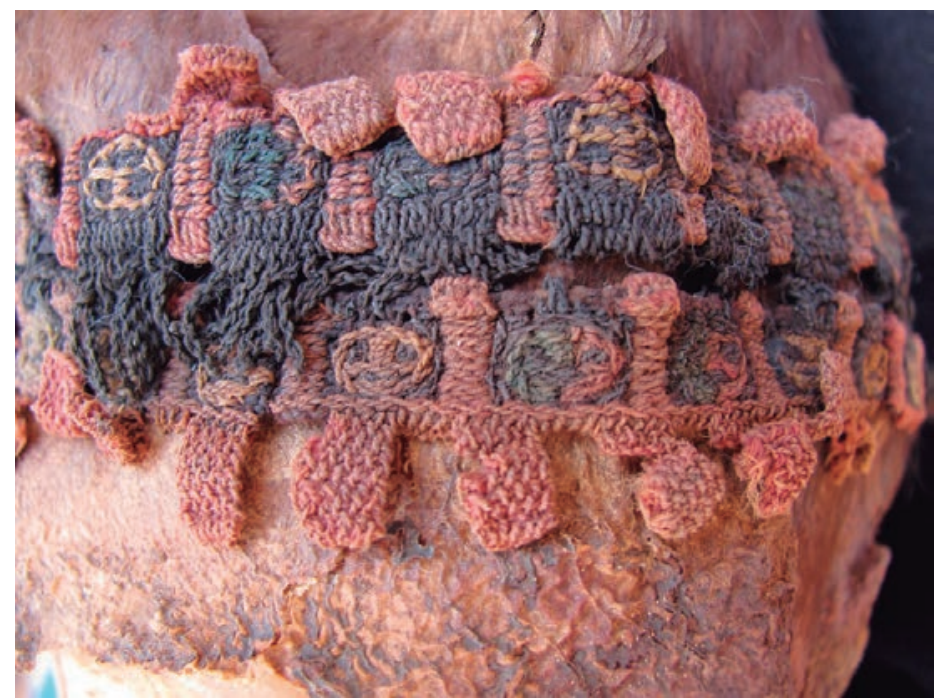

Figura 06. Representación de cabezas antropomorfas a modo de una posible imitación a motivos Paracas (L. M. Valdez) 
establecimiento de sitios fortificados durante el Periodo Intermedio Temprano. Por el momento, teniendo en cuenta que este tipo de materiales no son comunes en este valle, existe la posibilidad de que fueran introducidos por las poblaciones vecinas de los valles ubicados más al norte, pero siempre al contexto de una tradición local, con raíces en Hacha.

La poca visibilidad de las ocupaciones del Horizonte Temprano en el valle de Acarí parece obedecer a la posible presencia de estilos de cerámica que a la fecha no han sido bien definidos y que como tales permanecen todavía indistinguibles (Valdez, 2000 b, p. 21). Dicha variedad de cerámica debe tener sus raíces en el estilo Hacha y la continuación de aquella aún indistinguible debe ser el estilo que recurre en los sitios fortificados pertenecientes a las fases iniciales del Periodo Intermedio Temprano. Por lo tanto, todo material de origen norteño (Paracas) encontrado en Acarí es material foráneo, introducido al contexto de una tradición local. Su rara ocurrencia parece indicar a su vez que la interacción entre Acarí y los valles adyacentes ubicados más al norte fue poco fluida. En definitiva, todo parece indicar que al tiempo que en los valles más al norte de Acarí florecía la tradición Paracas, en Acarí había una población que no estaba asociada con Paracas.

\section{EL PERIODO INTERMEDIO TEMPRANO}

Primero en 1956 y luego en 1963, John H. Rowe reportó de la existencia de un grupo de sitios que compartían varios rasgos en común (Rowe, 1956, 1963). La primera de dichos rasgos es obviamente la extensión de los asentamientos que, en comparación a otros sitios contemporáneos de toda la costa sur, son extensos y nucleados (Valdez, 2009a, 2009b, 2010b, 2012a). La segunda característica también distinguible de los sitios de Acarí es la presencia de grandes muros perimétricos que encierran cada uno de estos asentamientos (Valdez, 2013, 2014, 2017a). Por ejemplo, al referirse a Tambo Viejo, Rowe (1963, p. 11) es explícito al mencionar a las fortificaciones construidas de piedras de campo y adobes (Valdez, 2012b, 2013, 2017a). Finalmente, el tercer aspecto en común entre todos estos sitios de Acarí es la presencia de una variedad de cerámica inicialmente identificada por Rowe (1963, p. 11) como la "antigua tradición local" (ver figura 07) y que en la opinión de Rowe es anterior a Nasca 3 (Valdez, 1998, 2009c).

Desde las iniciales observaciones hechas por Rowe, durante los últimos años se han efectuado avances substanciales que permiten visualizar mejor la situación del valle de Acarí en el tiempo en que los varios sitios fortificados (figura 08) fueron establecidos, ocupados y finalmente abandonados (Valdez, 1998, 2009a, 2010a, 2012b, 2017a). Dichos avances incluyen trabajos de excavación realizados en tres de los sitios fortificados y que pusieron a la luz evidencias novedosas que en conjunto ayudan a comprender, aunque de manera parcial, temas relacionados a la 
subsistencia, actividades, construcción, y sobre todo las formas de enterramiento (Valdez, 2005, 2006, 2009b).

Entre los avances más significativos destacan varios fechados absolutos obtenidos para 6 de los 8 sitios fortificados (Cuadro 03). Un total de 10 fechados absolutos han sido obtenidos para el sitio de Amato, 9 de los cuales provienen de contextos asociados con cuerpos decapitados (Valdez, 2009b) y uno pertenece al muro perimétrico excavado en la esquina noreste del sitio. En base a los fechados calibrados se puede sostener que Amato fue ocupado aproximadamente entre los años $150 \mathrm{AP}$ (antes del presente) y 200 de la era común (del presente). Por su parte, para el sitio de Tambo Viejo contamos con 4 fechados absolutos y todos asociados al muro perimétrico del lado oeste (Valdez, 2014). En base a estos fechados se puede sostener que el muro externo de Tambo Viejo fue establecido aproximadamente entre los años 50 AP y 240 del presente. Para el sitio de Coquimbo se dispone de solo 2 fechados y ambos asociados a un muro perimétrico. Estos fechados indican que Coquimbo habría sido ocupado entre los años 50 AP y 400 del presente.

Por su parte, para el sitio de Monte Grande Alto se dispone de 2 fechados absolutos y que provienen del muro perimétrico del sitio. Estos fechados sugieren que Monte Grande Alto fue ocupado aproximadamente entre los años 100 AP y 300 del presente. Para el sitio de Huarato también disponemos de 2 fechados absolutos, los que sugieren una ocupación del sitio entre los años 200 AP y 400 del presente, aproximadamente. Para el sitio de Molino, ubicado entre Coquimbo y Amato, solo existe un fechado que sugiere una ocupación del sitio aproximadamente entre los años 200 AP y 400 del presente.

Tal como se discutió con anterioridad (Valdez, 2009a, 2014, 2017a), y los fechados absolutos y calibrados lo confirman, los sitios fortificados de Acarí coexistieron. Es decir, todos estos sitios fueron establecidos alrededor de los años 150 antes del presente y fueron ocupados hasta aproximadamente los años 300 y 400 del presente. La ocurrencia de las mismas formas de construcción, especialmente los muros perimétricos, y un tipo de cerámica, ya indicaban que todos eran contemporáneos. Considerando que la mayoría de los fechados aquí presentados fueron obtenidos para determinar la edad de los muros que protegen a cada uno de estos asentamientos, es posible que el establecimiento inicial de cada uno de estos sitios se haya dado años mas antes. Para verificar esto se hace necesario obtener fechados similares para contextos domésticos. De ser así, es posible que en un futuro cercano se llegue a determinar que los asentamientos fortificados de Acarí fueron ocupados por aproximadamente 400 a 500 años.

La cerámica identificada como la "vieja tradición local" (ver figura 09), hoy la tradición Huarato (Valdez, 1998, 2000a), ocurre en asociación a los sitios fortificados. Los fechados tempranos de todos estos sitios confirman la inicial observación de 


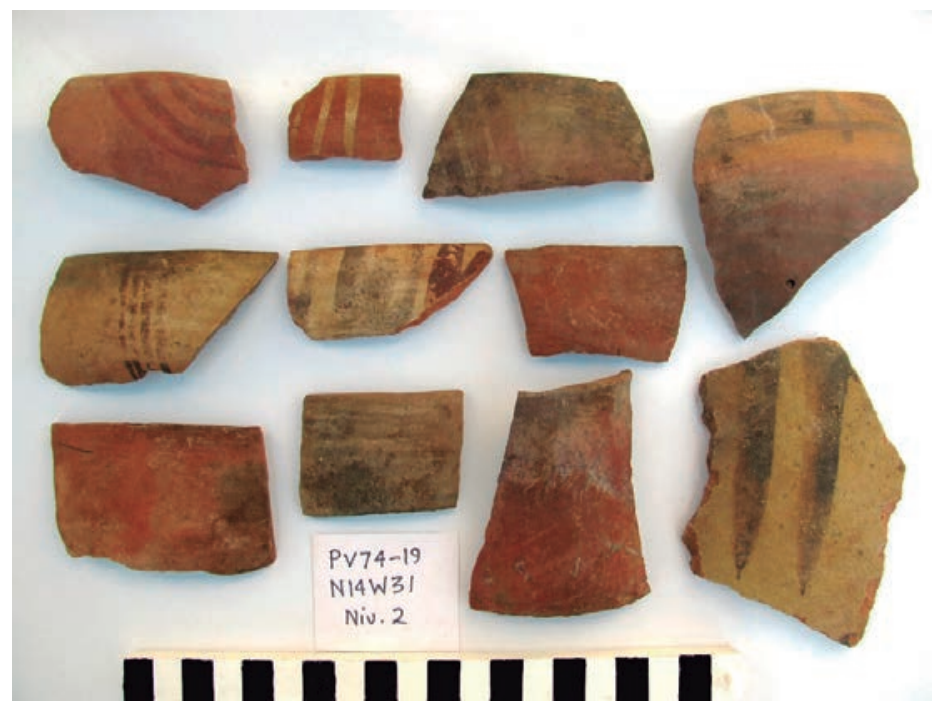

Figura 07. Cerámica en el estilo local proveniente de Amato; este es el estilo asociada a los asentamientos fortificados ocupados $d u$ rante las fases tempranas del Periodo Intermedio Temprano (L. M. Valdez)

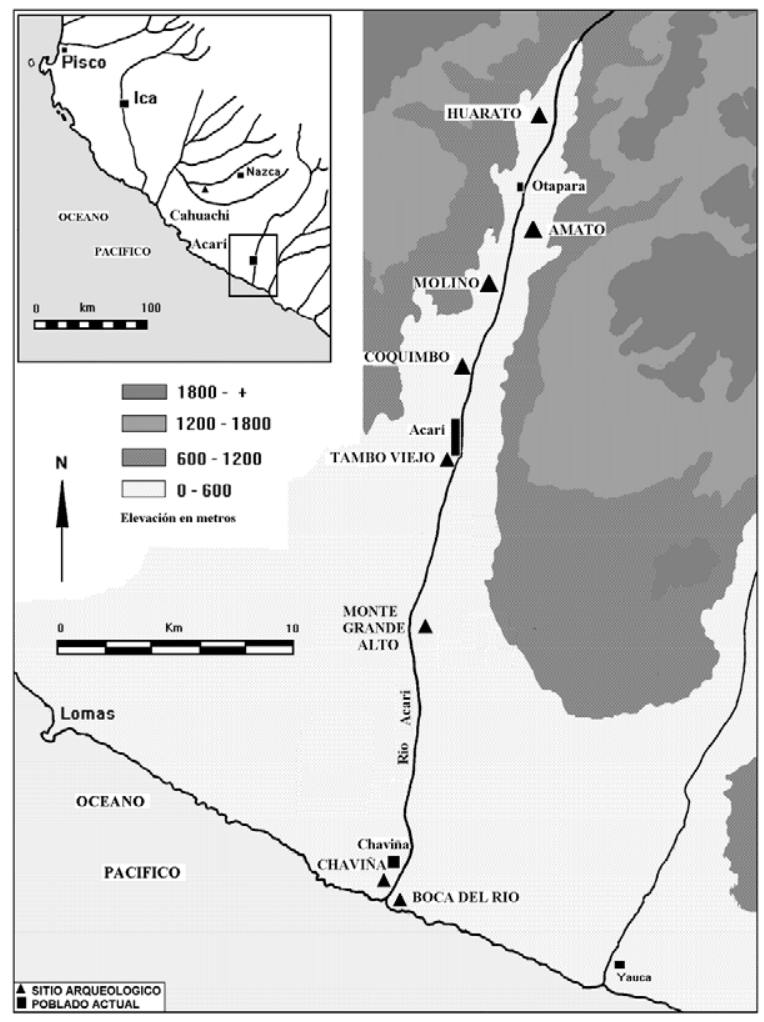

Figura 08. Ubicación de los sitios fortificados del Periodo Intermedio Temprano de Acarí (L. M. Valdez) 
Cuadro 3. Fechados radiocarbónicos calibrados y modelados de seis sitios del Periodo Intermedio Temprano del valle de Acarí.

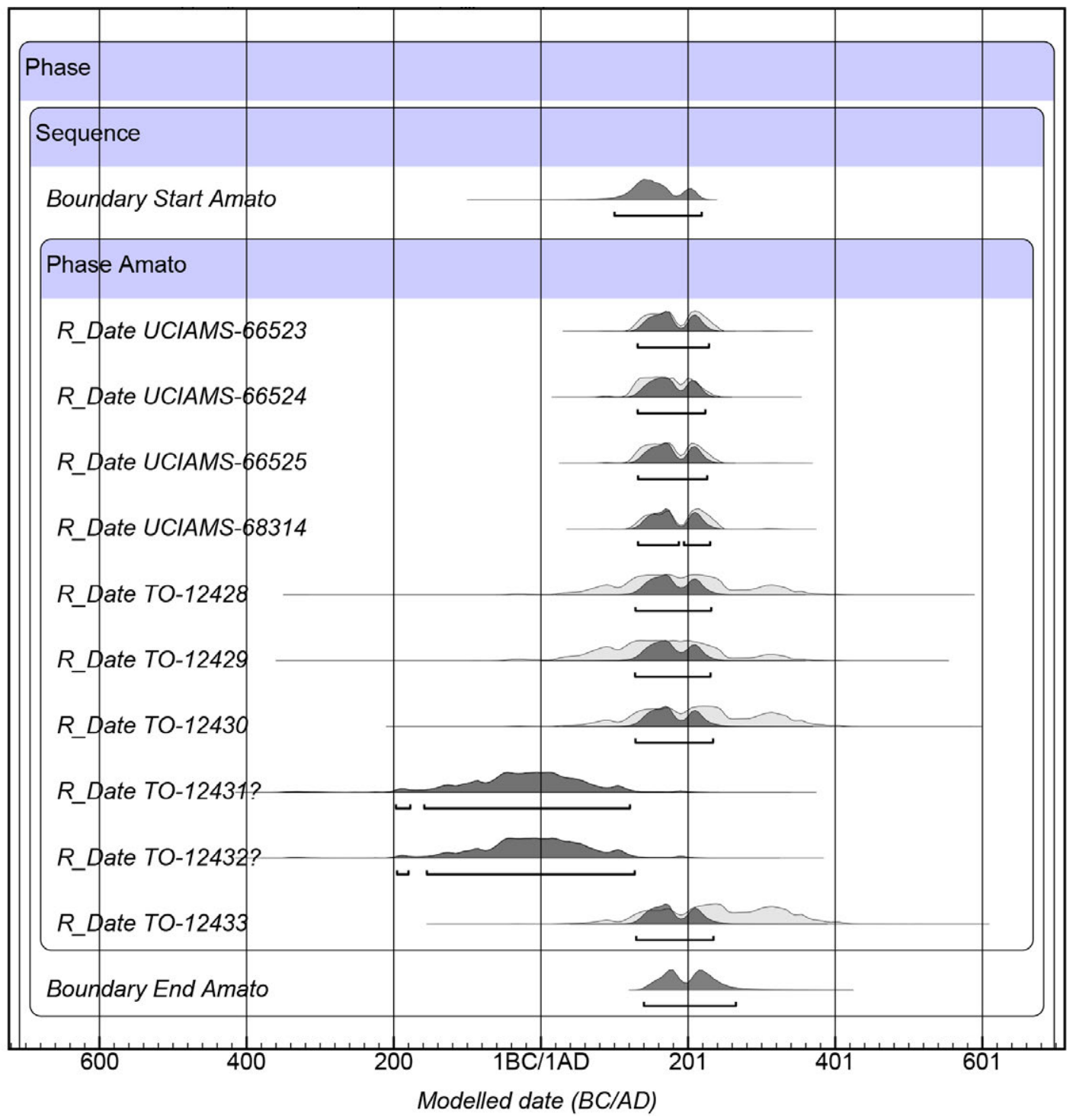




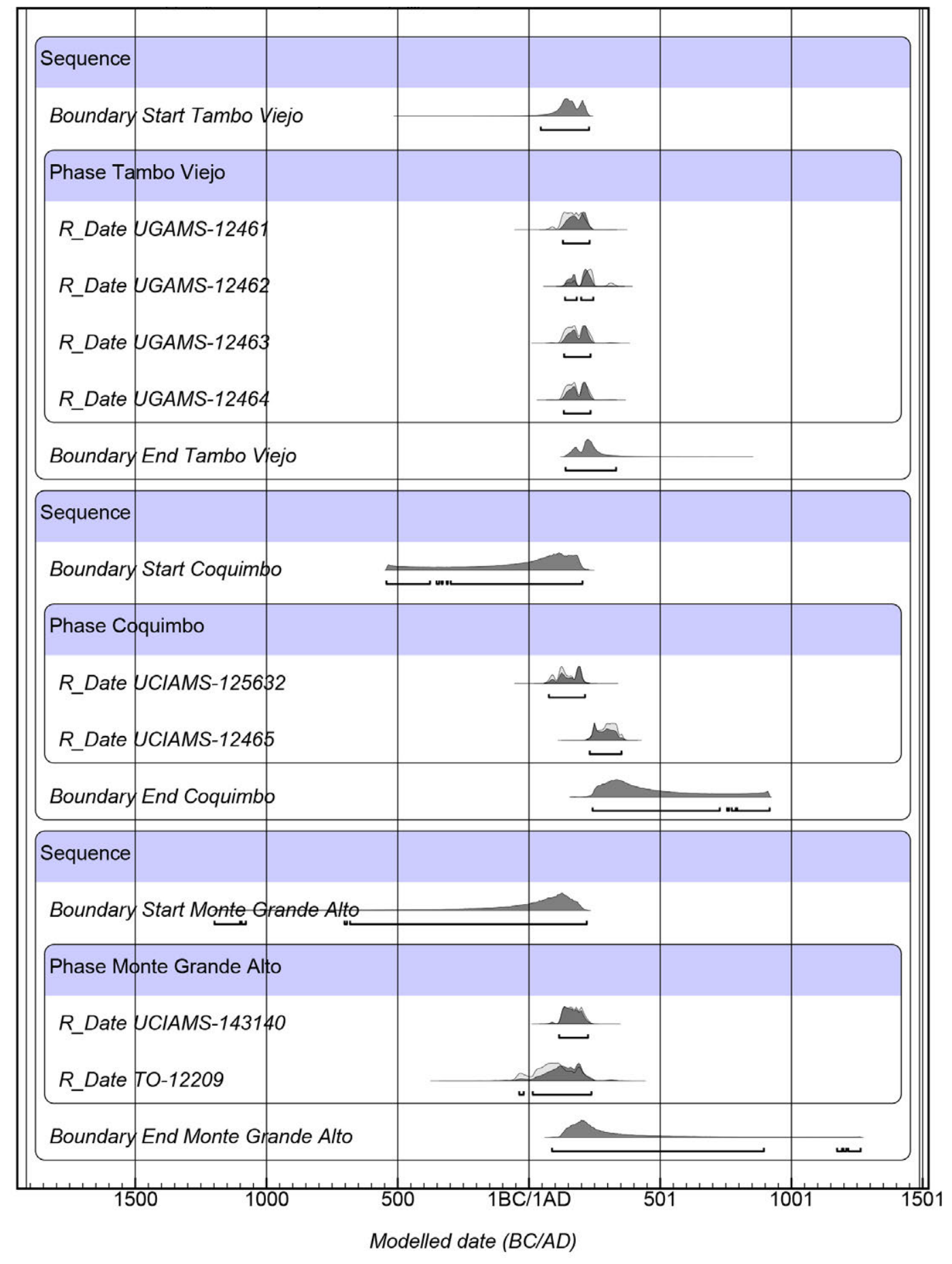




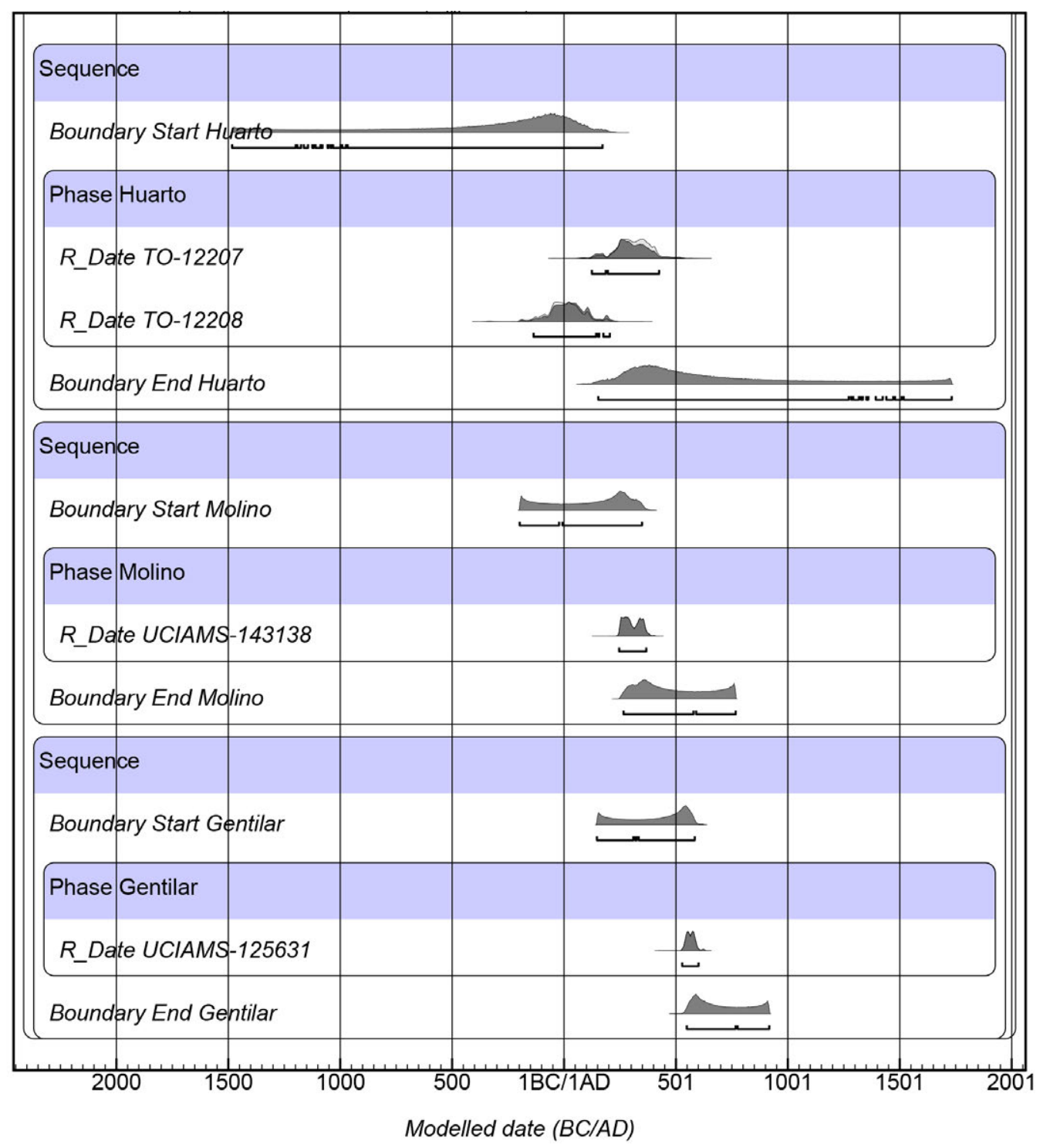

Rowe, quien inicialmente había sugerido que la cerámica local de Acarí es anterior a Nasca 3. Entretanto, la ocurrencia de cerámica con decoración incisa en tales contextos sugiere que la tradición local de Acarí posiblemente ya existió durante las fases finales del Horizonte Temprano, estando sus raíces tal vez en el estilo Hacha. Si esta observación tiene alguna validez, la cerámica local de Acarí presente en los sitios fortificados tiene una larga historia local. Fue al contexto de esta tradición local, la misma que continuó durante todo el Periodo Intermedio Temprano, que algunos ejemplares norteños fueron introducidos (Valdez, 2013: figura 7). En efecto, ejemplares Nasca continuaron llegando hacia Acarí (Figura 10), pero siempre al contexto de una tradición local y sin llegar a sustituirla. 
Las excavaciones realizadas tanto en Huarato como en Amato también han puesto al descubierto una excelente colección de restos macro-botánicos (ver cuadro 1). Como se discute en otro trabajo (Valdez, 2010b, p. 82), restos de estas plantas están presentes en otros sitios del Periodo Intermedio Temprano de toda la costa sur, lo que sugiere que a lo largo de esta región se había adoptado una selección de plantas como la base principal de la subsistencia. Es importante resaltar que la mayoría de estas plantas ya ocurren en Hacha.

La subsistencia estaba complementada con otros recursos locales y otros tal vez obtenidos mediante el intercambio. Entre los productos locales están los recursos marinos, especialmente los moluscos, así como otros provenientes del mismo valle, como son los camarones (Crypiops carmentharius) y peces (Valdez, 2009a, p. 268). Del mismo modo, las excavaciones en Huarato permitieron exponer pequeños recintos identificados como criaderos de cuyes (Valdez, 2009a, p. 266-267). Finalmente, están los restos de camélidos, al parecer alpacas, que posiblemente fueron obtenidos vía el intercambio.

Entre las actividades efectuadas por los residentes de los sitios fortificados resaltan los tejidos, la cestería, y la alfarería. Con algunas raras excepciones, los tejidos son simples y la materia prima fue esencialmente el algodón. Ocasionalmente se han encontrado agujas y ruecas utilizadas en el hilado. Por su parte, las excavaciones efectuadas en Amato pusieron al descubierto una excelente colección de cestos fabricados de varios tipos de fibras vegetales, en particular del junco (Typha angustifolia) y la totora (Scirpus californicus). Finalmente, la cerámica encontrada en todos estos sitios es aquella identificada por Rowe (1963, p. 11) como la 'antigua tradición local' de Acarí. Desafortunadamente, aún no se ha podido ubicar áreas identificables como talleres y mucho menos hornos utilizados en la quema de la cerámica. Por la importancia de la cerámica para esta discusión, abordo este aspecto en mayor detalle más adelante.

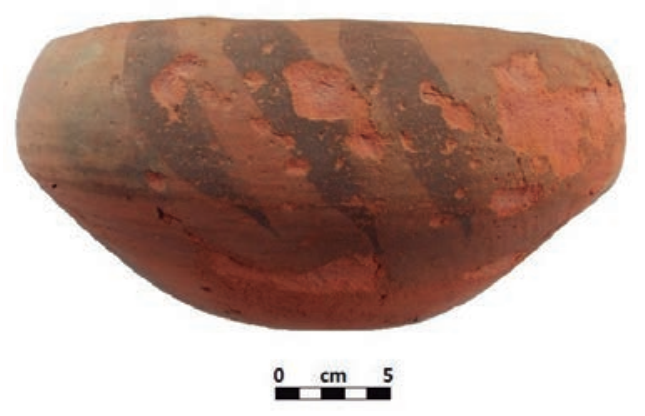

Figura 9. Cerámica en el estilo local proveniente de Monte Grande Alto, Acarí (L. M. Valdez) 


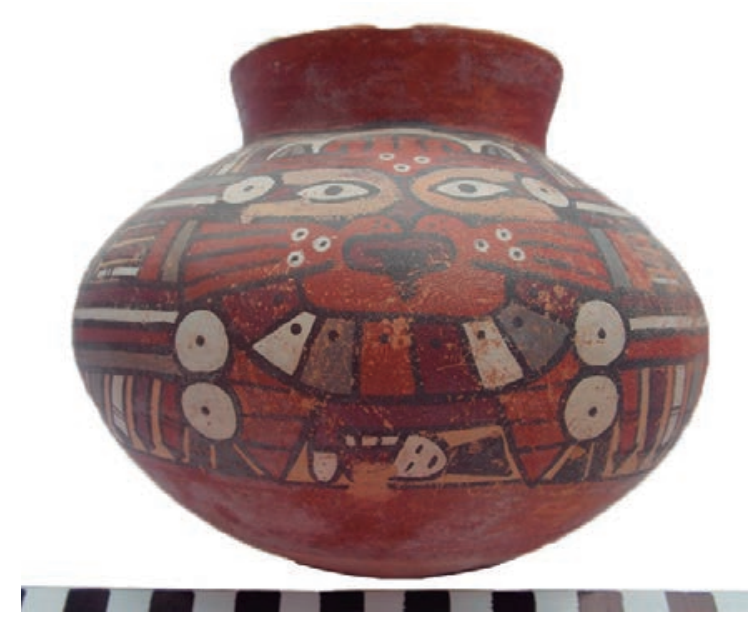

Figura 10. Cerámica Nasca proveniente de Huarato, Acarí (L. M. Valdez; escala en centímetros)

Con respecto a la construcción, todas las estructuras hasta hoy expuestas en los sitios fortificados de Acarí fueron establecidas teniendo como principal material de construcción los cantos rodados, disponibles a lo largo del curso del río. Ocasionalmente ocurren estructuras de adobes de varias formas, como son los típicos adobes cónicos y paniformes. No obstante que cada tipo de adobe fue utilizado de manera separada, también es posible encontrar ambos tipos de adobes en las mismas construcciones. Del mismo modo, existen estructuras que fueron edificadas combinando adobes y cantos rodados; este es el caso por ejemplo del recinto central de Amato, cuya cara interior es de adobes cónicos y la cara exterior de cantos rodados. Un caso similar se pudo observar en el recinto central de Monte Grande Alto. En todos los casos, los materiales de construcción fueron unidos con argamasa.

Finalmente, un aspecto que se ha esclarecido con mayor detalle es con respecto a las formas de enterramiento (Valdez, 2005, 2006). La excavación efectuada en Huarato en particular ha permitido exponer varios entierros intactos. Información adicional se ha recuperado de los sitios de Tambo Viejo, Amato y Monte Grande Alto. En conjunto, se ha podido identificar hasta cuatro tipos de enterramientos, que son:

i) entierros simples (en hoyos sin pared alguna y cubiertos con piedras),

ii) entierros en urnas (generalmente para subadultos),

iii) entierros con techos (en hoyos sin pared y con techos de caña) y, finalmente,

iv) entierros múltiples: se conoce sólo un caso proveniente de Tambo Viejo, donde se expuso una estructura de forma globular, con paredes de cantos rodados y 
un techo de caña (Valdez, 2006, p. 10). Merece anotar que entierros múltiples no se conocen para Nasca temprano (Isla, 2009, p. 131).

En Acarí, en todos los casos conocidos a la fecha, los cuerpos fueron envueltos en tejidos de manufactura simple y luego atados con una cuerda de fibra vegetal a la altura del abdomen. Fueron colocados en posición sentada, con las rodillas flexionadas hacia el pecho y las manos dispuestas a la altura de los pies (Valdez, 2006, p. 8). Sin excepción alguna, todos mantienen una orientación hacia el norte, dirección que guarda relación con la venida del Río Acarí. En la mayoría de los casos, los entierros carecen de ajuar funerario alguno; y cuando ocurren estos son botellas de mate o de otros productos agrícolas, particularmente de las raíces de yuca y achira, además del maní o las extremidades inferiores de camélidos (Valdez, 2006, p. 10). Ocasionalmente ofrendas de cuyes también fueron expuestas.

Todos los entierros hasta hoy puestos a la luz fueron sellados con una torta de barro, sobre la cual un pequeño canto rodado fue colocado como señal de la tumba. Por cuanto sobre la misma torta de barro se halló abundante ceniza y que la misma torta estaba quemada, es evidente que una vez sellada la tumba se prendió el fuego, con lo cual el ritual mortuorio parece haber concluido. Así como discutí en su oportunidad (Valdez, 2006, p. 13-15), existe una notable diferencia entre lo aquí señalado de manera bastante breve y las formas de enterramiento practicadas durante las fases tempranas Nasca (Carmichael, 1988, 1995; Isla, 2001; Reindel \& Isla, 2001; Orefici \& Drusini, 2003). Por ejemplo, para Nasca temprano se desconoce de la presencia del fuego al final del ritual mortuorio.

Los fechados absolutos y calibrados obtenidos para varios de los sitios fortificados de Acarí permiten también conocer dichos asentamientos fueron abandonados aproximadamente alrededor de los años 300 y 400 del presente. De todos, Amato parece haber sido el sitio que fue abandonado antes que los demás. Tal vez la masacre registrada en el sitio (Valdez, 2009b) marcó el final prematuro del sitio, mientras que asentamientos próximos a Amato, como Huarato y Molino parecen haber continuado existiendo, por lo menos por 100 años más.

Una de las posibles causas para el abandono de los sitios fortificados parece haber sido la violencia que obligó a sus habitantes a establecer sistemas defensivos en forma de grandes muros perimétricos (Valdez, 2010a, 2010c, 2012a). Chaviña fue una excepción y continuó siendo ocupado hasta inicios del Horizonte Medio (Valdez, 1994, 2009b, p. 405). Además de documentar muros con adobes cónicos, típicos de las estructuras de las fases tempranas del Periodo Intermedio Temprano, Neira y Coelho (1972/73, p. 142) citan una fecha de $450 \pm 70$ EC para Chaviña, la misma que es posterior a las fechas disponibles para Amato, Huarato, Coquimbo, Tambo Viejo y Monte Grande Alto. 
Teniendo en cuenta que no existen fortificaciones contemporáneas a los arriba mencionados en los valles ubicados al norte de Acarí, y por cuanto las fortificaciones son consideradas como una de las mejores manifestaciones de la existencia del conflicto (Arkush \& Stanish, 2005, p. 15; Elliott, p. 2005, p. 298-99; Flannery \& Marcus, 2003, p. 11803; Haas, 2001, p. 340; LeBlanc, 2006, p. 443-45), todo parece indicar que el conflicto en Acarí fue local y entre los residentes de los varios asentamientos vecinos. De la evidencia proveniente de Amato (Valdez, 2009b, 2009d, 2012b, 2017a), es también posible sostener que el conflicto estaba orientado a capturar la mayor cantidad posible de prisioneros, quienes posteriormente fueron decapitados. Es difícil determinar si la decapitación tenía alguna relación con las cabezas trofeo, aunque teniendo en cuenta que la obtención de las cabezas trofeo fue relativamente común en toda esta región (Proulx, 2001) no se descarta dicha vinculación. Sin embargo, es oportuno anotar que en Amato se hallaron dos cabezas humanas sin las características típicas de una cabeza trofeo (Valdez, et al., 2010), lo que nuevamente hace difícil afirmar si las cabezas de los decapitados de Amato fueron transformadas en trofeos.

De existir alguna relación, y considerando que es Chaviña el sitio donde ocurre la mayor cantidad de cabezas trofeo (Neira \& Coehlo, 1972/73) y que además Chaviña continuó siendo ocupado al tiempo que los demás sitios fortificados quedaron aban-

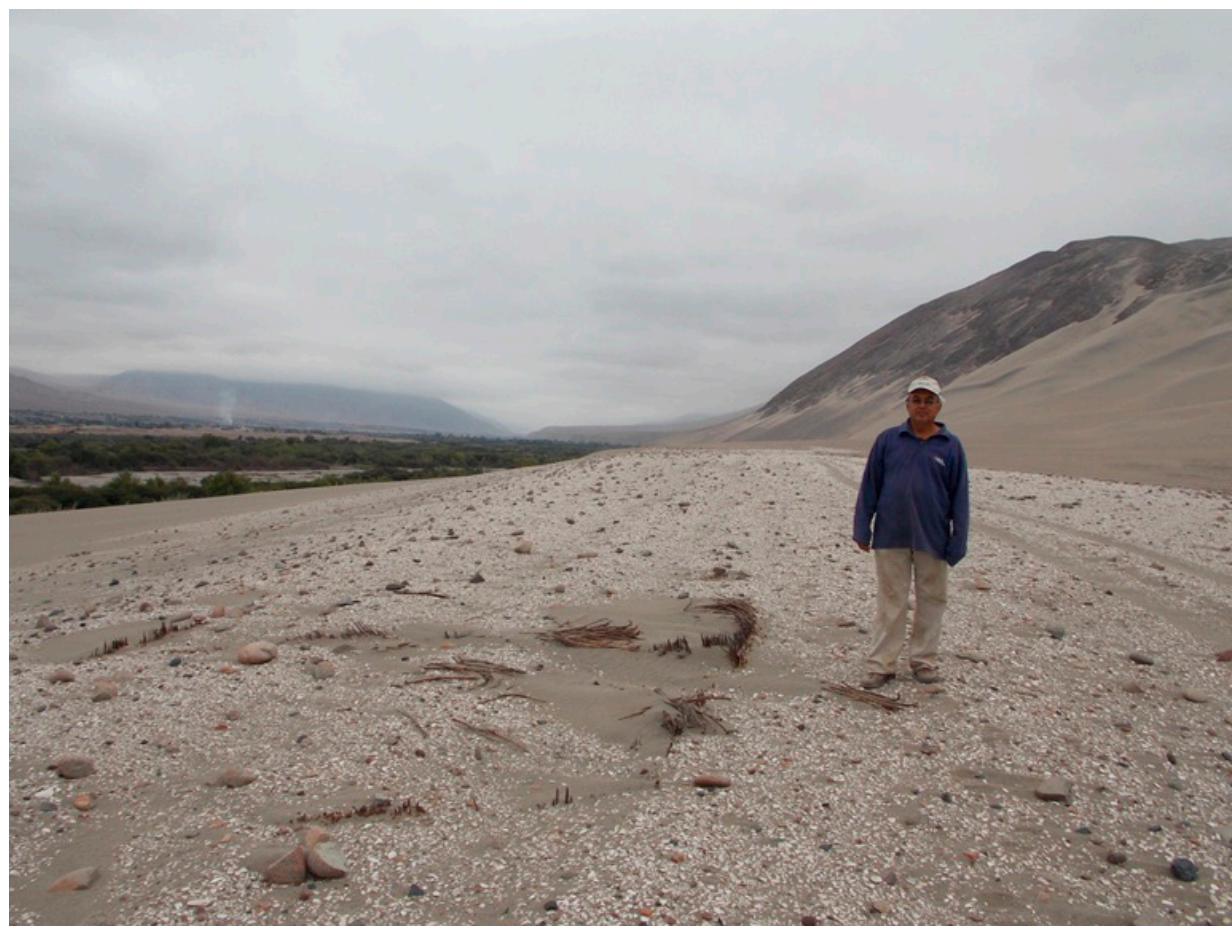

Figura 11. Sitio arqueológico de Gentilar ocupado a finales del Periodo Intermedio Temprano (L. M. Valdez) 
donados, existe la posibilidad de que Chaviña tal vez tuvo una decisiva intervención - tal vez violenta - en el abandono de los varios asentamientos fortificados de este valle. Del mismo modo, es importante anotar que mientras Chaviña continuó siendo un asentamiento fortificado, nuevos asentamientos fueron establecidos en el valle. Dichos asentamientos son diferentes de los que existieron previamente: estos no sólo son pequeños, sino también carecen de las fortificaciones. Uno de tales asentamientos es Gentilar (figura 11), establecido en las inmediaciones de Hacha y cuyas estructuras fueron edificadas de quincha (Valdez, 1994, 2017b).

Tal como se puede observan en el cuadro 3, el único fechado del que se dispone para Gentilar hace de este un asentamiento posterior a los demás. Efectivamente, el fechado absoluto sugiere que Gentilar fue ocupado entre los años 450 y 600 del presente, aproximadamente. A diferencia de los otros asentamientos mencionados en esta sección, Gentilar no es un asentamiento fortificado (Valdez, 1994). Mas bien, Gentilar fue un asentamiento establecido luego del abandono de los asentamientos fortificados. Al tiempo que Gentilar fue ocupado, existieron en el valle otros asentamientos similares, pero definitivamente distintos de los asentamientos fortificados. La abundante presencia de los restos de moluscos en sitios como Gentilar, aún considerando su ubicación a $20 \mathrm{~km}$ del océano, sugiere que una sequía prolongada afectó al valle de Acarí, y esta pudo haber sido una de las causantes del conflicto que terminó con los asentamientos fortificados.

\section{LA ANTIGUA TRADICIÓN LOCAL DE ACARÍ}

En comparación con otros restos materiales recuperados en contextos arqueológicos, la cerámica ocupa un lugar de particular importancia por diversas razones, entre las que se cuenta su abundancia y su fácil preservación (Lanning, 1967, p. 24). Además, la cerámica es por excelencia un material que exhibe cambios de orden estilístico, muy útiles para determinar las secuencias de ocupación de los antiguos asentamientos humanos, así como diferencias en su manufactura. Este último aspecto, la forma como la cerámica fue manufacturada, es de particular importancia en tanto que cada población, o cultura, tiene sus propias técnicas de elaborar su cerámica. Dichas técnicas, o conocimiento, son transmitidas de una generación a otra, y en las sociedades de menor escala, a menudo es de mujer a mujer o en su efecto de madre a hija (DeBoer, 1990; David \& Kramer, 2001). Durante este proceso, las personas participantes en la producción comparten no sólo el conocimiento de cómo se hace (o cómo se debe hacer) la cerámica, sino sobre todo de cómo dicha población produce su cerámica. Esta particularidad hace que exista una marcada variación entre los tipos de cerámica producida entre dos o más regiones, no obstante que estas sean vecinas.

En la costa sur, la población Nasca tenía sus propias formas de producir la cerámica (Carmichael, 1998; Vaughn \& Neff, 2004; Vaughn \& Linares Grados, 2006; Vaughn 
et al., 2006), la misma que es distinguible del estilo Topará, también producida de una forma muy particular, y que de acuerdo a Massey $(1986$, p. 87) es distinta de Nasca. En Acarí se observa un caso similar, en tanto que la cerámica presente en los sitios fortificados es distinta del estilo Nasca (Valdez, 2009c). Todo parece indicar que iniciándose alrededor del Formativo tardío y continuando durante el Periodo Intermedio Temprano, por lo menos tres distintas tradiciones culturales florecieron y coexistieron en la costa sur del Perú. Cada una de estas tradiciones culturales se distingue entre sí en varios aspectos (Valdez, 2006), aunque de manera particular en el tipo de cerámica que manufacturaron. Cada una de estas poblaciones disponía de un repertorio tecnológico que le permitió producir la cerámica de la manera ideal, la misma que fue aquella que aprendieron dentro de un contexto social específico. Considerando que cada población tiene su propia forma ideal de producir la cerámica, dicha forma posiblemente también sirvió como un medio que los distinguió de las otras tradiciones culturales vecinas.

La cerámica producida en el valle de Acarí, identificada como la tradición Huarato (Valdez, 1998, 2000a, 2009c), es lo suficientemente distinta de las otras dos tradiciones alfareras. Aunque a la fecha no se ha logrado ubicar un centro (o áreas) de producción de cerámica, todo parece indicar que tal actividad fue efectuada a nivel de cada unidad domestica. Tecnológicamente, especialmente en comparación con la cerámica Nasca, el estilo local presenta un acabado bastante simple. Por lo general, entre los desgrasantes destaca la arena (que no necesariamente es seleccionada o fina), feldespato y mica. El color de la pasta es gris, rojo opaco y negro, siendo común observar una banda oscura en la parte central lo que indica que las vajillas fueron cocidas en hornos abiertos y a temperaturas relativamente bajas. A diferencia de los fragmentos Nasca temprano, la fractura de los tiestos locales no es uniforme. Además, en ambas superficies es notable no sólo la presencia de mica, sino también de líneas horizontales producto del alisado y estriado. La superficie recibió un ligero pulido y en algunos casos también un bruñido, pero sin llegar a ocultar las líneas producto del estriado. Asimismo, se observa un ligero baño de engobe rojo aguado que por lo común se limita a una de las superficies (dependiendo de la forma de las vajillas) pero sólo a la sección media y superior de las vasijas. En contraste al fino engobe que caracteriza al estilo Nasca temprano, el engobe de la cerámica local es definitivamente distinto y fue pobremente preparado y aplicado a la ligera. Por último, los pocos y simples motivos que decoran a las vasijas locales aparecen plasmados sobre una superficie que no es uniforme y/o lisa.

Es preciso anotar que para el caso Nasca tampoco se conoce un sólo centro de producción de cerámica (Carmichael, 1998). Aunque no se cuenta con evidencias concretas, otros han sostenido que la cerámica policroma Nasca fue producida por especialistas y el centro de producción habría sido Cahuachi (Vaughn \& Neff, 2004; Vaughn et al., 2006). Durante las varias temporadas de campo que participé en las excavacio- 
nes efectuadas en Cahuachi, bajo la dirección de Giuseppe Orefici, nunca observé un solo horno Nasca destinado a la producción de cerámica. Por lo tanto, considero que los argumentos que pretenden asegurar que Cahuachi fue el centro de producción de la cerámica policroma Nasca deben y tienen que tomarse con mucha cautela.

\section{¿UNA ETAPA TRANSICIONAL ENTRE EL FORMATIVO Y EL PERIODO INTER- MEDIO TEMPRANO?}

Paracas y Nasca son parte de una sola tradición donde existe un fuerte elemento de continuidad entre cualquiera de dos fases sucesivas, y dicha continuidad existe entre Ocucaje fase 10 y Nasca fase 1 (Menzel, Rowe \& Dawson, 1964, p. 251).

El estilo Paracas que define a la cultura del mismo nombre está caracterizado por la cerámica, la misma que, como fue observado inicialmente por Menzel, Rowe y Dawson (1964, p. 251), se distingue por su pintura poscocción. En contraste, el estilo Nasca, que de acuerdo a Sawyer (1961, p. 278; Menzel, Rowe \& Dawson, 1964, p. 251) es una continuación de Paracas, se caracteriza por el engobe aplicado antes de la cocción. De lo mencionado en la sección anterior, queda evidente que dichas particularidades todavía no están del todo bien definidas en Acarí, generalmente a razón que su ocurrencia en este último sigue siendo raro o muy esporádico.

De la información disponible, viene quedando clara la presencia de tres estilos alfareros en Acarí. El primero y el más antiguo en el estilo Hacha. No obstante que Robinson (1994) sostiene que hay 2 variedades de dicho estilo, considero que el estilo Hacha es único, pero diverso en cuanto a formas se refiere. Este es un aspecto que necesita ser resuelto lo antes posible para trazar la secuencia de formas de utensilios presentes en este valle. El segundo estilo es el menos representativo y como consecuencia, tanto su ubicación cronológica exacta, como su asociación cultural siguen siendo poco claras. Este es el caso de los pocos fragmentos de cerámica cuyos diseños están representadas mediantes incisiones y que vienen apareciendo en los asentamientos tradicionalmente considerados del Periodo Intermedio Temprano, caso Amato. Por un lado, las muestras hasta hoy recuperadas son suficientemente distintas del estilo Hacha; sin embargo, está por determinarse si sus raíces están en Hacha. Por otro lado, si estas piezas son representativas del estilo Paracas, su rara ocurrencia en Acarí deja abierta la posibilidad de que en Acarí existía una población local y que fue al contexto de dicha población local que llegaron algunos ejemplares de piezas norteñas. Como tales, los pocos ejemplares de dicho estilo deben ser piezas foráneas manufacturadas fuera de los límites de Acarí.

Finalmente, y tal como ya se anotó líneas atrás, está la cerámica asociada a los sitios fortificados. Dicho estilo, si bien mantiene algunos acercamientos, especialmente en cuanto a forma se refiere, a otras tradiciones alfareras de los valles ubicados más al norte (Van Gijseghem, 2006: figuras 03, 04, 05 y 09; Massey, 1992: figuras 
05, 06 \& 09), existe una marcada diferencia en cuanto al acabado y sobre todo a la decoración de las vasijas se refiere. Los motivos que decoran las vajillas de Acarí están definitivamente ausentes en las vajillas Nasca temprano o Paracas tardío. Motivos decorativos como las incisiones en círculos y las representaciones naturalistas, comunes en Paracas tardío y Nasca temprano, respectivamente, son desconocidos en Acarí. En su lugar, los motivos presentes son bastante simples e incluso abstractos.

Estas variaciones son bastante significativas y apuntan hacia la presencia de un estilo definitivamente diferente de los presentes en los valles ubicados más al norte. Merece insistir que el estilo es producto de lo aprendido dentro de la sociedad, y es a su vez aceptado y sancionado por la misma. Visto de esta manera, los diseños que decoran las vajillas son símbolos que no sólo representan la idiosincrasia de una población, sino que sobre todo tienen significado. Siguiendo este razonamiento, las poblaciones que comparten experiencias comunes, desarrollan concepciones comunes, las mismas que son comprensibles y significativas a todos sus miembros. Dichos símbolos o motivos son transmitidos de una generación a otra, sufriendo en el proceso ligeras modificaciones. En este sentido, la cerámica es un excelente medio que permite no sólo plasmar los símbolos representativos de una cultura, sino también es portadora de la identidad de quienes la manufacturaron y la utilizaron. En efecto, para cada población sólo existe una forma aceptada de producir la cerámica, y esta incluye la manera como la vajilla es (o debe) ser decorada. Si bien toda población es consciente de que pueblos vecinos, a su vez potencialmente enemigos, producen sus vajillas manteniendo sus propios criterios locales, se entiende que para la población local sólo existe una forma y esa es como ellos, los locales, la manufacturan.

Manteniendo esta perspectiva, la presencia de varios estilos de cerámica en la costa sur entre los finales del Formativo e inicios del Intermedio Temprano abre la posibilidad de la presencia de varias tradiciones culturales co-existiendo en la región de la costa sur. Y, como ninguna población representa una isla - por más que estén separadas por desiertos inhóspitos - las poblaciones siempre están en contacto e interacción (Barth, 1969). Esta última no sólo abre la posibilidad de que miembros de diferentes tradiciones culturales participen en el intercambio de sus miembros (matrimonio), sino sobre todo en el intercambio de ideas (DeBoer, 1990). Cuando esto ocurre, se puede anticipar ciertos acercamientos en el material cultural producido por varias tradiciones culturales, quienes a su vez buscan mantener sus propias formas de identidad. Por lo tanto, la presencia de los adobes cónicos o la misma práctica de la toma de las cabezas humanas a lo largo de toda la costa sur no están fuera de lo normal.

Para el caso de la costa sur, siempre se ha trabajado desde una perspectiva que anticipa la existencia de una sola cultura. Esta perspectiva condiciona al investigador a buscar determinados elementos materiales, enfoque que a su vez impide visuali- 
zar la manifestación local en su real dimensión. Este modelo anticipa una incursión desde el norte, a modo de migración (Silverman, 1994; Van Gijseghem, 2006, p. 426), y deja a entender que los valles ubicados más al sur estaban despoblados o que sus poblaciones eran bastante reducidas (Silverman, 1991) y poco creativas. Para el caso de Palpa, sin embargo, se ha demostrado la presencia Paracas desde sus fases iniciales (Isla, Reindel \& de la Torre, 2003).

En Acarí, por mucho tiempo se ha trabajado con los ojos puestos en busca de material cultural representativo de la cultura Nasca; y toda vez que un fragmento Nasca fue encontrado, este ha sido enfatizado a costa de todo un estilo que en definitiva es distinto de Nasca. Esta interpretación hizo que Nasca fuera visto como un estado expansivo que abarcó desde Pisco por el norte hasta Acarí por el sur (Proulx 1968; Massey 1986). Así fue como la interpretación arqueológica generó todo un estado Nasca temprano, militarista y expansivo. Al establecer un imaginario estado Nasca temprano, se olvidó por completo que las culturas del pasado -al igual que las actuales- posiblemente también mantuvieron lazos de contacto y que dichos contactos tenían la capacidad de transportar objetos materiales lejos de sus centros originales de producción (Carmichael, 1992). En base a esta experiencia, se hace evidente que es poco productivo, y definitivamente peligroso, hacer trabajos de investigación manteniendo expectativas preconcebidas. Lo que viene emergiendo en la costa sur no es una homogeneidad; por el contrario, se hace cada vez más evidente la presencia de varias tradiciones locales (Proulx, 2008) que posiblemente fueron política y económicamente independientes. Dichas entidades locales, si bien independientes, formaron parte de un nexo que existió articulado y que compartió varios rasgos culturales, propios de las tradiciones culturales adyacentes.

Finalmente, para apreciar mejor los desarrollos culturales de cada uno de los valles de una región como la costa sur se hace imprescindible ir más allá de la cerámica. Si bien la cerámica es útil para discutir varios aspectos culturales de una antigua sociedad, es también importante reconocer que existen otros medios y otros materiales culturales. Solo del análisis de cada una de estas manifestaciones materiales se podrá afirmar algo significativo acerca de las culturas que analizamos y sobre las cuales tenemos el privilegio de reflexionar. Mientras esto no suceda, mientras sigamos invirtiendo la mayor parte de nuestros esfuerzos sólo en el estudio de una manifestación cultural, seguiremos lejos de apreciar la dinámica del desarrollo cultural y sobre todo sus particularidades, detalles estos que por más pequeños que sean tienen mucho significado.

Agradecimientos: Mis gracias se hacen extensivas para todas las personas que de una u otra forma han hecho posible la realización de mis estudios en Acarí. Esta incluye a Martín Roque, Ángel Iglesias, Eber Meléndez y Alan Chalco. Mi esposa, Katrina Bettcher y mis hijos Kai y Kía, siempre han estado conmigo, aún cuando 
me encontraba haciendo los trabajos de campo. Extiendo mi agradecimiento a mi hija Kía por los arreglos a las figuras aquí incluidas. Finalmente, dedico este trabajo a toda la población de Acarí por haberme permitido ser parte de ellos por todos estos largos años.

\section{REFERENCIAS BIBLIOGRÁFICAS}

Arkush, E. N. \& Stanish, C. (2005). Interpreting conflict in the Andes: Implications for the archaeology of warfare. Current Anthropology, (46), 3-28.

Barth, F. (1969). Introduction. En F. Barth (Ed.). Ethnic Groups and Boundaries (pp. 9-38). Boston: The Little Brown Series in Anthropology, Brown \& Company.

Bennett, W. C. (1948). The Peruvian co-tradition. En W. C. Bennett (Ed.). A Regional Appraisal of Peruvian Archaeology (pp. 1-7). Memoirs of the Society for American Archaeology.Washington, D. C.

Beresford-Jones, D. (2011). The Lost Woodlands of Ancient Nasca: a case study in ecological and cultural collapse. Oxford: The British Academy of Oxford University Press.

Burger, R. L. (1995). Chavin and the Origins of Andean Civilization. London: Thames \& Hudson.

Carmichael, P. H. (1988). Nasca mortuary customs: death and ancient society on the south coast of Peru. Ph. D. Dissertation, Department of Archaeology, University of Calgary, Canada.

Carmichael, P. H. (1992). Local tradition during the Early Intermediate Period in the south coast of Peru. Willay, 37-38, pp. 4-6.

Carmichael, P. H. (1995). Nasca burial patterns: social structure and mortuary ideology. En T. Dillehay, (Ed.). Tombs for the Living: Andean mortuary practices (pp. 161-187). Washington, D.C. Dumbarton Oaks.

Carmichael, P. H. (1998). Nasca ceramics: production and social context. En: I. Shimada (Ed.). Andean Ceramics: Technology, Organization, and Approaches. NASCA Research Papers in Science and Archaeology, Supplement to vol. 15, pp. 213-231. Pennsylvania: University of Pennsylvania Museum of Archaeology and Anthropology.

Carpio, A. (1942). Datos sobre la arqueología de los valles de Acarí y Yauca. Actas y Trabajos Científicos del XXVII Congreso Internacional de Americanistas, vol. I, pp. 435-529. Lima.

David, N. \& Kramer, K. (2001). Ethnoarchaeology in Action. Cambridge: Cambridge University Press.

DeBoer, W. R. (1990). Interaction, imitation, and communication as expressed in style: the Ucayali experience. En M. W. Conkey \& C. A. Hastorf (Eds.), The 
Uses of Style in Archaeology (pp. 82-104). Cambridge: Cambridge University Press.

Elliott, M. (2005). Evaluating evidence for warfare and environmental stress in settlement pattern data from the Malpaso Valley, Zacatecas, Mexico. Journal of Anthropological Archaeology, 24, pp. 297-315.

Flannery, K. V. \& Marcus, J. (2003). The origin of war: New 14 C dates from ancient Mexico. Proceedings of the National Academy of Sciences (USA) 100:11801-11805.

Fung Pineda, R. (1988). The Late Preceramic and Initial Period. En R. W. Keatinge, (Ed.), Peruvian Archaeology (pp. 67-96). Cambridge: Cambridge University Press.

Grossman, J. W. (1972). An ancient gold worker's tool kit: the earliest metal technology in Peru. Archaeology, 25(4), 270-275.

Grossman, J. W. (1985). Demographic change and economic transformation in the south-central highlands of pre-Huari Peru. Nawpa Pacha, 21, pp. 45-126.

Kroeber, A. L. (1944). Peruvian Archaeology in 1942. New York: Viking Fund Publications in Anthropology 4.

Haas, J. (2001). Warfare and the evolution of culture, En G. M. Feinman \& T. D. Price (Eds.), The archaeology at the millennium: A sourcebook (pp. 329-50). New York: Kluwer Academic/Plenum.

Isla, J. (2001). Una tumba Nasca en Puente Gentil, valle de Santa Cruz, Perú. Beitrage Zur Allgemeinen Und Vergleichenden Archaologie, 21, pp. 207-239.

Isla, J. (2009). From hunters to regional lords: funerary practices in Palpa, Peru. En M. Reindel \& G.A. Wagner (Eds.). New technologies for Archaeology (pp. 119139). Heidelberg: Springer-Verlag Berlin.

Isla, J., Reindel, M \& De la Torre, J. (2009). Jauranja: un sitio Paracas en el valle de Palpa, costa sur del Perú. Beitrage Zur Allgemeinen Und Vergleichenden Archaologie, 23, pp. 227-274.

Lanning, E. P. (1967). Peru before the Incas. New Jersey: Prentice-Hall, Inc., Englewood Cliffs.

LeBlanc, S. A. (2006). Warfare and the development of social complexity. En E. N. Arkush \& M. W. Allen, (Eds.) The Archaeology of warfare: Prehistories of raiding and conquest (pp. 437-68). Gainesville: University Press of Florida.

Lothrop, S. K. \& Mahler, J. (1957). Late Nazca burials in Chaviña, Peru. Papers of the Peabody Museum of Archaeology and Ethnology, 50(1). Camdridge, Massachusetts: Harvard University. 
Lumbreras, L. G. (1974). The Peoples and Cultures of Ancient Peru. Washington, D.C.: Smithsonian Institution Press.

Massey, S. A. (1986). Sociopolitical change in the Upper Ica Valley, B.C. 400 to 400 A.D.: Regional States on the South Coast of Peru. Ph. D. Dissertation, University Microfilms International, Ann Arbor, Michigan.

Massey, S. A. (1992). Investigaciones arqueológicas en el valle alto de Ica: periodo intermedio temprano 1 y 2. En D. Bonavía, (Ed.). Estudios de Arqueología Peruana (pp. 215-235). Lima: Fomciencias.

Menzel, D. (1959). The Inca occupation of the south coast of Peru. Southwestern Journal of Anthropology, 15(2), 125-142.

Menzel, D. (1976). Pottery Style and Society in Ancient Peru: Art as a Mirror of History in the Ica Valley, 1350-1570. Berkeley: University of California Press.

Menzel, D. (1977). The archaeology of ancient Peru and the work of Max Uhle. Berkeley: R. H. Lowie Museum of Anthropology, University of California.

Menzel, D. \& Riddell, F. A. (1986). Archaeological Investigations at Tambo Viejo, Acari Valley, Peru, 1954. Sacramento: California Institute for Peruvian Studies.

Menzel, D., Riddell, F. A., \& Valdez, L. M. (2012). El centro administrativo Inca de Tambo Viejo. Arqueología y Sociedad, 24, pp. 403-436. Lima: Museo de Arqueología y Antropología, UNMSM.

Menzel, D., Rowe, J. H., \& Dawson, L. E. (1964). The Paracas Pottery of Ica: a study in style and time. Berkeley \& Los Angeles: University of California Press.

Neira, M. \& Coelho, V. P. (1972-73). Enterramientos de cabezas de la cultura Nasca. Revista do Museu Paulista, (20), 109-142.

Orefici, G. \& Drusini, A. (2003). Nasca: hipótesis y evidencias de su desarrollo cultural. Brescia: Centro Italiano Studi e Ricerche Archaeologiche Precolombiane.

Piacenza, L. (2002). Evidencia botánicas en asentamientos Nasca. Boletín del Museo de Arqueología y Antropología, 5(1), 3-13. Lima: Universidad Nacional Mayor de San Marcos.

Proulx, D. A. (1968). Local differences and time differences in Nasca pottery. University of California Publications in Anthropology 5. Berkeley.

Proulx, D. A. (1989). Nasca trophy heads: victims of warfare of ritual sacrifice? En D. Tkaczuk \& B. Vivian (Eds.). Cultures in Conflict (pp. 73-85). Calgary: Chacmool, the Archaeological Association of the University of Calgary.

Proulx, D. A. (2001). Ritual uses of trophy heads in ancient Nasca society. En E. Benson \& A. Cook (Eds.). Ritual sacrifice in ancient Peru, (pp. 119-36). Austin: University of Texas Press. 
Proulx, D. A. (2008). Paracas and Nasca: regional cultures on the south coast of Peru. En H. Silverman \& W.H. Isbell (Eds.). Hanbook of South American Archaeology (pp. 563-585). New York: Springer.

Reindel, M. \& Isla, J. (2001). Los Molinos Und La Muña: Zwei Siedlunszentren der Nasca-kultur in Palpa Sudperu. Beitrage Zur Allgemeinen Und Vergleichenden Archaologie, 21, 241-319.

Riddell, F. A. \& Valdez, L. M. (1987). Hacha y la ocupación temprana del valle de Acarí. Gaceta Arqueológica Andina, 16, 6-10.

Riddell, F. A. \& Valdez, L. M. (1988). Prospecciones Arqueológicas en el valle de Acarí, costa sur del Perú. Sacramento: California Institute for Peruvian Studies.

Robinson, R. W. (1994). Recent excavations at Hacha in the Acari Valley, Peru. Andean Past, 4, 9-37.

Rowe, J. H. (1954). Max Uhle, 1856 - 1944: A Memoir of the Father of Peruvian Archaeology. University of California Publications in American Archaeology and Ethnology, 46(1). Berkeley \& Los Angeles: University of California.

Rowe, J. H., (1956). Archaeological explorations in southern Peru, 1954-1955. American Antiquity, 22, 135-151.

Rowe, J. H. (1963). Urban settlements in Ancient Peru. Ñawpa Pacha, 1, pp. 1-27.

Rowe, J. H. (1967). An interpretation of radiocarbon measurements on archaeological samples from Peru. En J. H. Rowe \& D. Menzel (Eds.), Peruvian Archaeology: selected readings (pp. 16-30). Palo Alto: Peek Publications.

Sawyer, A. R. (1961). Paracas and Nazca iconography. En S. K. Lothrop, (Ed.). Essays in Pre-Columbian Art and Iconography, (pp. 269-298). Cambridge, Massachusetts: Harvard University Press.

Silverman, H. (1977). Estilo y estado: el problema de la cultura Nasca. Informaciones Arqueológicas, 1, 49-78.

Silverman, H. (1991). The Paracas problem: archaeological perspectives en A. Paul, (Ed.). Paracas, Art and Architecture (pp. 349-415). Iowa City: University of Iowa Press.

Silverman, H. (1994). Paracas in Nazca: new data on the Early Horizon occupation of the Río Grande de Nazca drainage, Peru. Latin American Antiquity, (5), 359-382.

Silverman, H. (1996). The Formative period on the south coast of Peru: a critical review. Journal of World Prehistory, 10(2), 95-146.

Strong, W. D. (1957). Paracas, Nazca, and Tiahuanacoid cultural relationships in south coastal Peru. Memoirs of the Society for American Archaeology 13, Vol. 22 (4), Part 2. 
Tello, J. C. (1942). Origen y desarrollo de las civilizaciones prehistóricas Andinas. Actas y Trabajos Científicos del XXVII Congreso Internacional de Americanistas, Vol. I, pp. 589-720. Lima.

Valdez, L. M. (1994). Investigaciones Arqueológicas en Gentilar, Acarí. Boletín de Lima, 91-96, pp. 351-361.

Valdez, L. M. (1996). The Pictographs from Hacha, Peru. En B. D. Low \& R. Wondrasek (Eds.). Proceedings and Abstracts: Six Annual APALA Student Conference, (pp. 98102). University of Saskatchewan, Saskatoon.

Valdez, L. M. (1998). The Nasca and the Valley of Acarí: cultural interaction on the Peruvian south coast during the first four centuries A.D. Ph.D. Dissertation, Department of Archaeology, University of Calgary, Calgary.

Valdez, L. M. (2000a). La tradición Huarato de Acarí y sus relaciones con Nasca. Arqueología y Sociedad, (13), 159-71.

Valdez, L. M. (2000b). La arqueología del valle de Acarí, Arequipa. Boletín del Museo de Arqueología y Antropología, 3(12), 19-25.

Valdez, L. M. (2005). Patrones funerarios del Periodo Intermedio Temprano del valle de Acarí. Corriente Arqueológica, (1), 43-60.

Valdez, L. M. (2006). Los vecinos de Nasca: entierros de la tradición Huarato del valle de Acarí, Perú. Bulletin de l'Institut Français d'Etudes Andines, 35(1), 1-20.

Valdez, L. M. (2009a). La investigación arqueológica en el valle de Acarí y la contribución de Francis A. Riddell. En M.S. Ziólkowski, J. Jennings, L.A. Belan \& A. Drusini (Eds.). Arqueología del Área Centro Sur Andina: Actas del Simposio Internacional. Andes 7, Boletín del Centro de Estudios Precolombinos de la Universidad de Varsovia (pp. 255-279).

Valdez, L. M. (2009b). Walled settlements, buffer zones, and human decapitation in the Acari Valley, Peru. Journal of Anthropological Research, 65(3), 389-416.

Valdez, L. M. (2009c). El significado social de la cerámica Nasca temprano en el valle de Acarí, Perú. Revista de Antropología Chilena, (20), 15-36.

Valdez, L. M. (2009d). Conflicto y decapitación humana en Amato (valle de Acarí, Perú). Bulletin de l'Institut Français d'Etudes Andines, 38(2), 177-204.

Valdez, L. M. (2010a). Asentamientos fortificados y conflicto en el valle de Acarí, Perú. Ponencia presentada a la V Reunión de Teoría Arqueológica en América del Sur, Caracas, Junio 21-25, 2010.

Valdez, L. M. (2010b). Los silos de almacenamiento de Huarato, valle de Acarí, Perú. Revista de Investigaciones, (7), 73-90. Lima: Centro de Estudiantes de Arqueología, Universidad Nacional Mayor de San Marcos. 
Valdez, L. M. (2010c). Circunscripción medioambiental y decapitación humana en la costa sur del Perú. En R. Romero \& T. P. Svendsen, (eds.) Arqueología en el Perú: Nuevos aportes para el estudio de las sociedades Andinas prehispánicas (pp. 131-150). Lima: Anheb Impresiones.

Valdez, L. M. (2012a). The earliest fortified settlements of the Acari Valley, Peru. Ponencia presentada al 40th. Midwest Annual Conference on Andean and Amazonian Archaeology and Ethnohistory. The Field Museum of Chicago, Febrero $24-26,2012$.

Valdez, L. M. (2012b). Fortified Settlements and the Origins of Conflict in the Acari Valley, Peru. Ponencia presentada a South American Archaeology Seminar. Institute of Archaeology, University College London, Mayo 19, 2012.

Valdez, L. M. (2013). Tambo Viejo: un asentamiento fortificado en el valle de Acarí, Perú. Arqueología Iberoamericana, (19), 3-23.

Valdez, L. M. (2014). The earliest fortifications of the Peruvian South Coast. Ñawpa Pacha, 34(2), 201-222.

Valdez, L. M. (2017). The earliest fortified settlements of the south coast of Peru. En Adam K. Benfer (Ed.). War and Peace: Conflict and Resolution in Archaeology (pp. 16-46). Proceedings of the 45th Annual Chacmool Archaeology Conference. The Archaeology Association of the University of Calgary, Calgary.

Valdez, L. M. (2017b). Asentamientos Fortificados y Conflicto en el valle de Acarí, Perú. Editorial Académica Española, Mauritius.

Valdez, L. M. (2018). Dorothy Menzel y el estudio del estado Wari. Ñawpa Pacha, (38), 109-134.

Valdez, L. M., Menzel, D. \& Riddell, Francis A. (2014). La cerámica del centro administrativo Inca de Tambo Viejo. Arqueología y Sociedad, 27, pp. 227-254.

Valdez, L. M., Williams, J. S., Bettcher, K. J. \& Dausse, L. (2010). Decapitación y cabezas humanas del valle de Acarí, Perú. Arqueología y Sociedad, (22), 39-53.

Van Gijseghem, H. (2006). A frontier perspective on Paracas society and Nasca ethnogenesis. Latin American Antiquity, 17(4), 419-444.

Vaughn, K. J., Conlee, A. C., Neff, H., \& Schreiber, K. (2006). Ceramic production in ancient Nasca: provenience analysis of pottery from the early Nasca and Tiza cultures through INAA. Journal of Archaeological Science, (33), 681-689.

Vaughn, K. J. \& Linares Grados, M. (2006). 3,000 years of occupation in upper valley Nasca: excavations at Upanca. Latin American Antiquity, 17(4), 595-612. 
Vaughn, K. J. \& Neff, H. (2004). Tracing the clay source of Nasca polychrome pottery: results from a preliminary raw material survey. Journal of Archaeological Science, (31), 1577-1586.

Von Hagen, V. (1955). Highway of the Sun. Duell, Sloan and Pearce, New York.

Willey, G. R. (1971). An Introduction to American Archaeology (vol. 2). South America. Prentice-Hall, Inc., Englewood Cliffs, New Jersey.

\section{SOBRE EL AUTOR}

\section{Lidio M. Valdez}

Licenciado en Arqueología por la Universidad Nacional de San Cristobal de Huamanga, y Doctor en Filosofía (1998), University of Calgary (Canadá). Sus trabajos más recientes son en relación a la ocupación Inka en el Valle de Acari.

Actualmente es profesor adjunto en el Department of Anthropology and Archaeology, University of Calgary, Canada. 